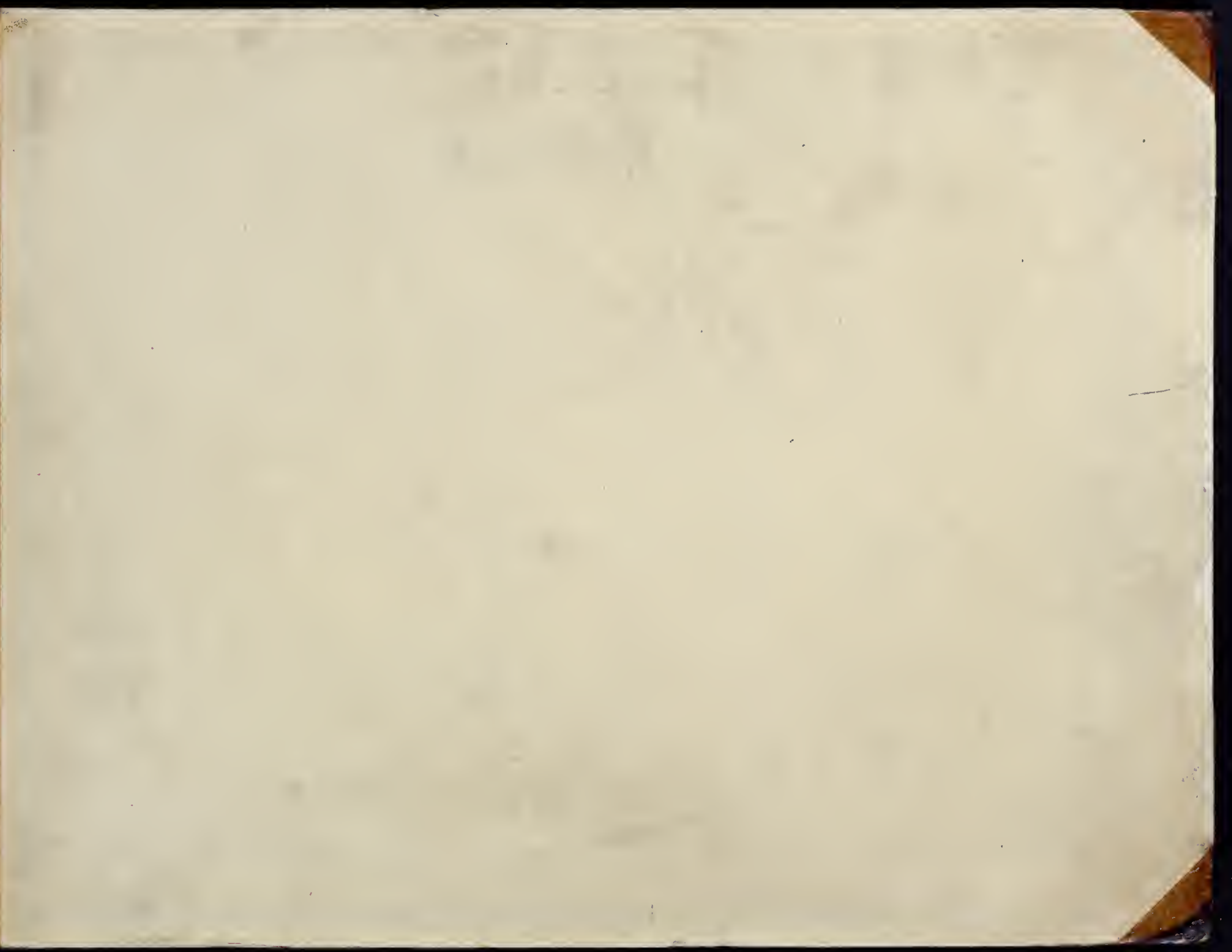




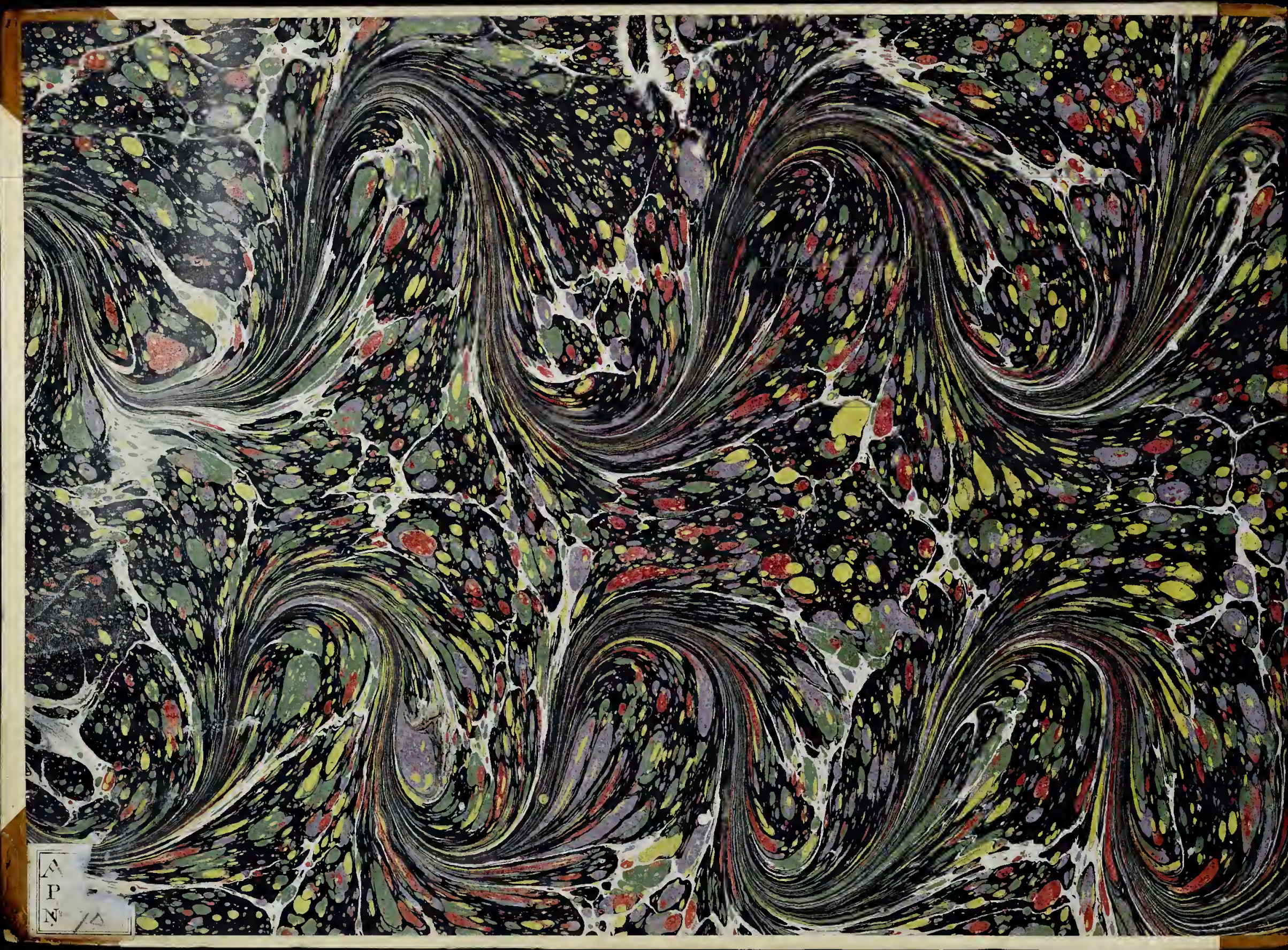




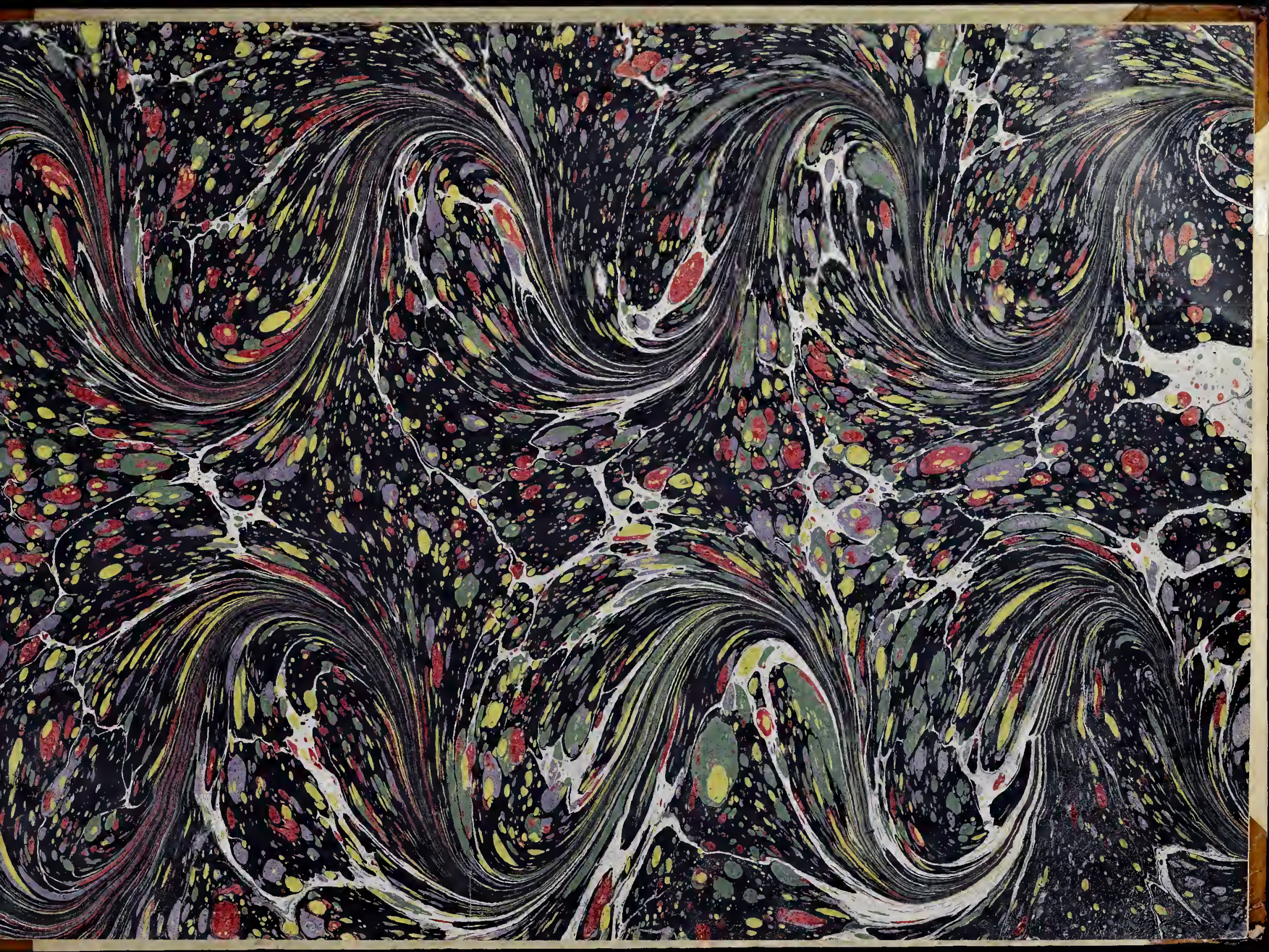





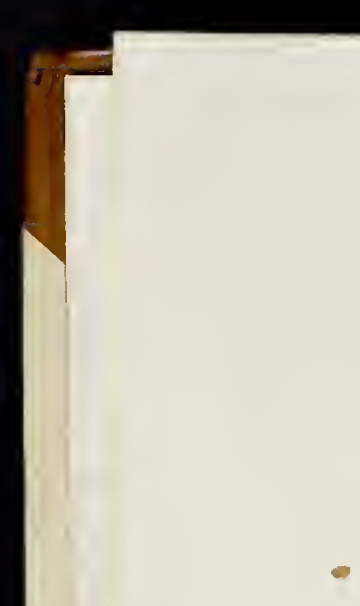




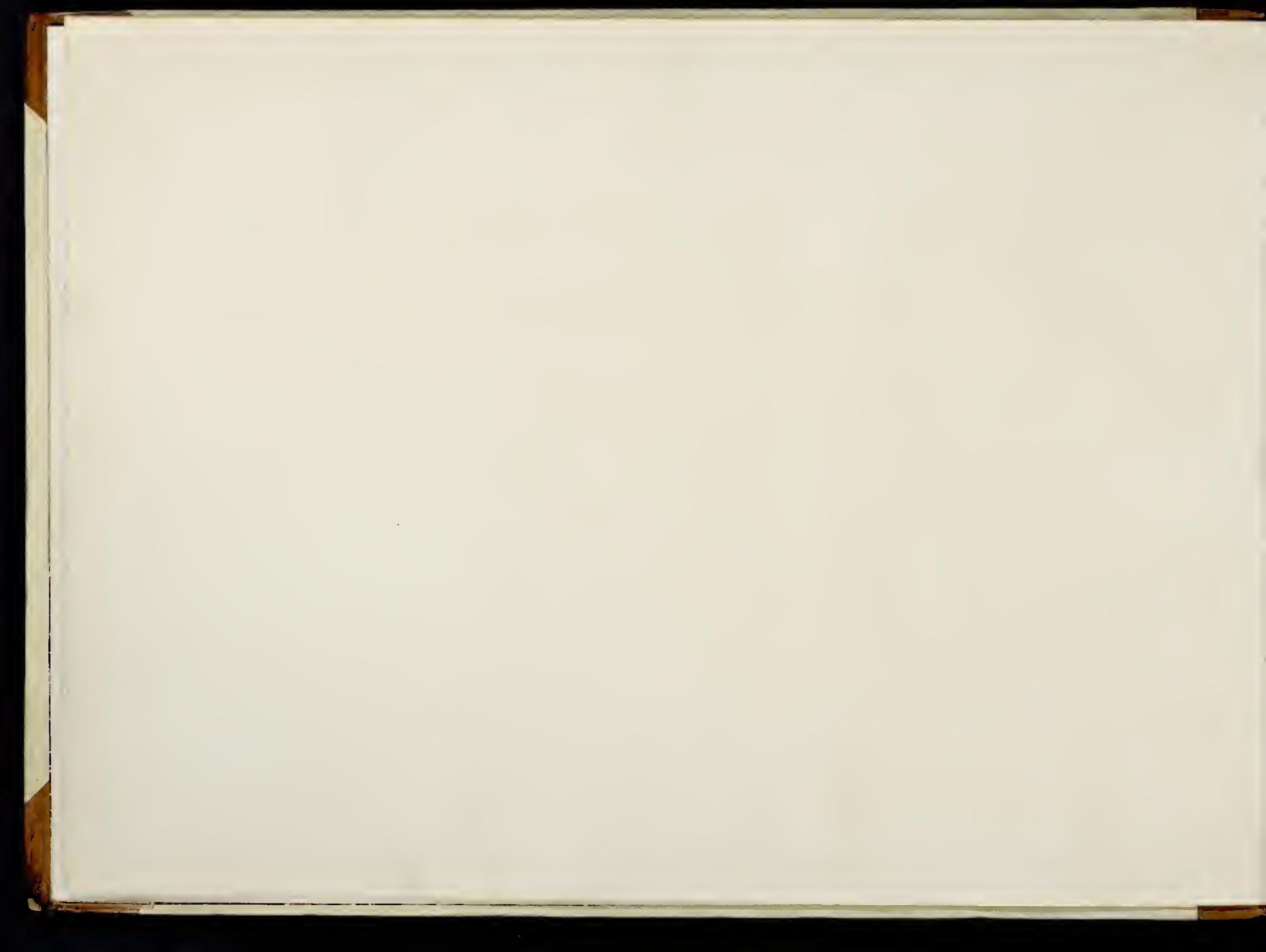




\section{A COLLECTION}

OF

\section{VARIOUS FORMS OF STOVES,}

USED FOR FORCING

PINE PLANTS, FRUIT TREES, AND PRESERVING TENDER EXOTICS :

INTENDED AS WELL FOR THE USE OF AMATEURS, AS THAT OF STUDENTS

IN TIIE

ART OF GARDENING.

THE PLATES ACCOMPANIED BY AMPLE LETTER-PRESS, AND A CORRECT METHOD SHEWN

FOR DRAWING THEIR

ELEVATIONS AND SECTIONS, FROM THE PLANS.

WITH TIIE PARTS AT LARGE.

$B \mathcal{T}$ W. ROBERTSON.

LONDON:

PUBLISHED AS THE ACT DIRFCTS, JAN, 1, 179 9, AT R. ACKERMANA'S GALIERY,

No. 101, STRAND. 


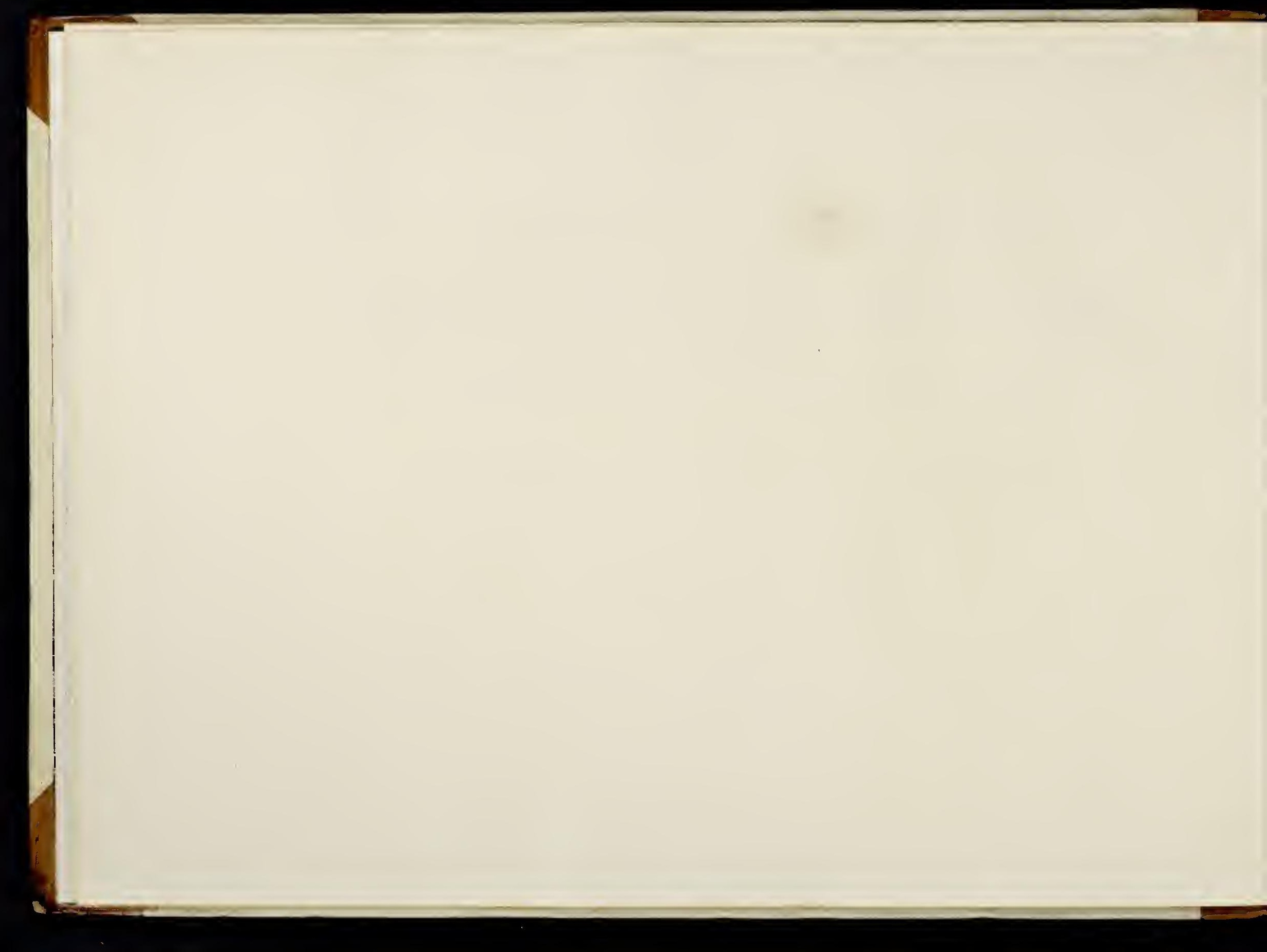




\section{P R E F A C E.}

THE following $W_{\text {ork }}$ is respectfully offered to the Public, under the idea of its being the first of the description published in this kingdom. Engravings of many of their forms are to be met with, it is true, in many works on gardening; but it can also bc with truth asserted, that (with very few exceptions) they serve to convey no more than a general idea of their forms; which may satisfy a theorist, but is insufficient for a practical gardcner; who must not only be very conversant in the principles on which thcy should be constructed, but also, be able to design them, and superintend their erection. In this country, this is particularly necessary, where gardening has been brought to great perfection; and where there is much emulation in this department of it. The following performance, is an attempt to obviate such deficiency, by conveying correct ideas of several of their dispositions, and their particular parts; and also offering several hints for their improvement. A simple method is shewn for drawing, not only the elevations, but sections, from the plans, with accuracy; and the whole endeavoured to be rendered equally useful to the Amateur or Professional Artist.

N. B. Several original designs arc introduced in the course of the work, and the manner of shewing most of them is uncommon. 


\section{The Method of Draiving the Elevation and Section from the Plan. is as follows.}

The Plan being drawn, and its measures ascertained, a vertical line must be drawn parallel to the end of it, and the measures transferred from the plan to it ; then the line of the back wall is produced beyond it, and the leg of the compass being placed in their intersection, all the measures are again successively transferred to this last, (as shewn in Plan of the first Plate,) and the internal disposition of the section determined, by drawing up lines from it, (the heights of the different parts supposed known). Horizontal lines drawn from the section determine the height of thc elevation and section, on the back wall; and the place of the arches in front is found, by drawing up lines from the front of the Plan. With a very superficial knowledge of drawing, accurate sections, and elevations of these and other buildings, may be readily made by this method.

One thing it is necessary to premise, which may be looked upon as an axiom in constructing those buildings; that the less air they contain, or the lower they are, (consistently with the size of the plants they are intended to receive,) with so much the greater effect can they be worked, and with so much the less expence can they be supported. Hence the reason that Pine Pits, are at present in such estimation. 


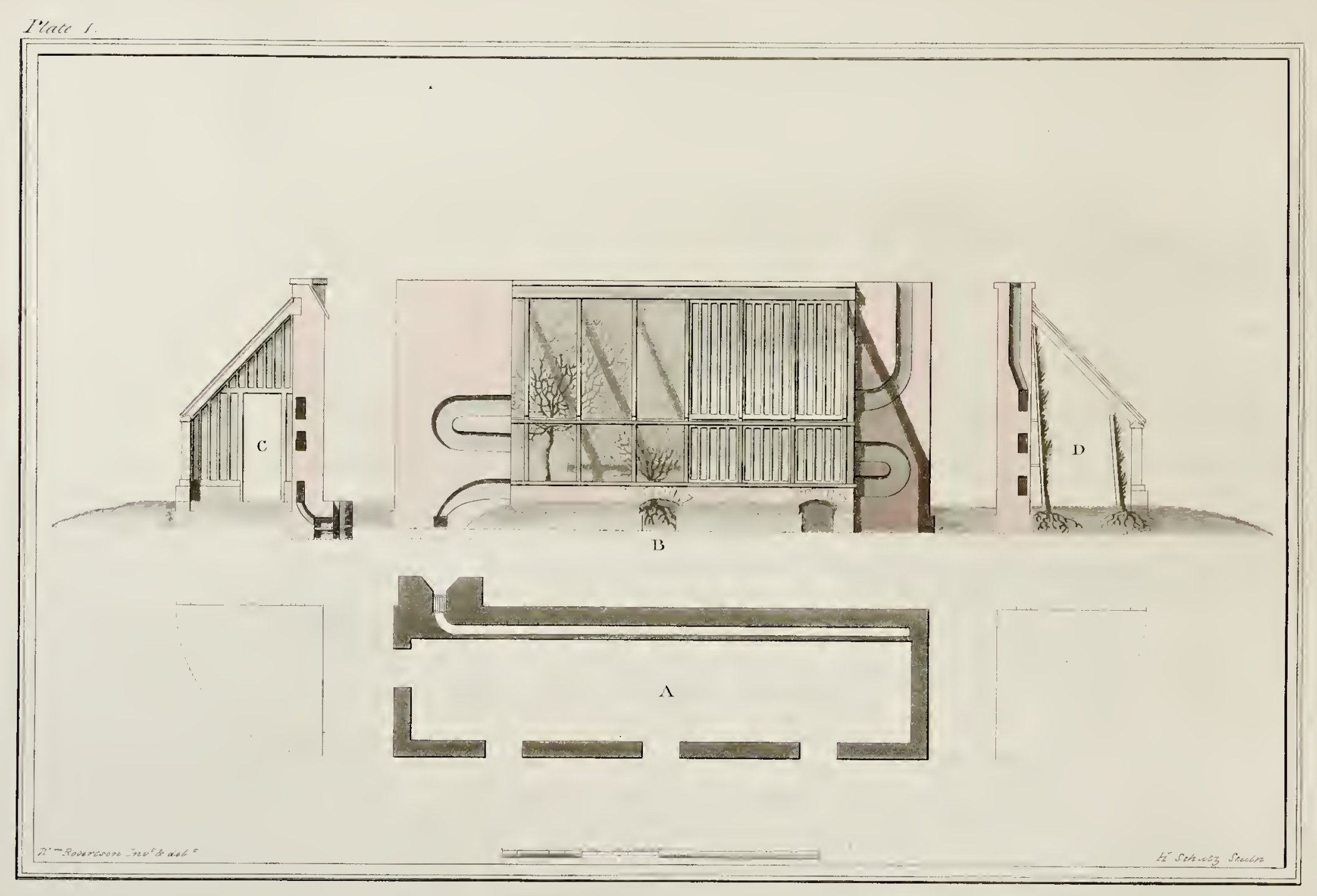




\section{PLATE I.}

THE simplest form of a Peach House, frequently worked by the sun's heat alone, and may be continued to any length thought proper: when fire heat is used, divisions may be thrown across the house, at forty-five or fifty feet apart, which one moderate fire will effectually warm, on account of the narrowness of the house, where the trees are not to be forced early. Two sets of trees are planted inside, and the entire border within reserved for those on the back wall; the roots of the trees in front run through the arches into the outside border. The scale at the foot of each Plate will give the measures correctly of each part of the following designs.

A, the plan, shews the breadth of the stove, the furnace, fiue, and arches in front.

$B$, the elevation, part with the sashes on, and part uncovered; a tree on the front, its roots seen in the border through the arch; another on the back wall. At each end a section of the back wall, shewing the revolutions of the flue after ascending from the furnace.

$\mathrm{C}$, end section, through the furnace, slewing the rafter and wall-plate* of the back, the uprights, and crown plates of the front.

D, section through the centre, the trees seen on their treillages.*

* Plate XXII. 


\section{PLATE II.}

A PIT for forcing peaches: a form much esteemed, and used at present both for pines as well as peaches: (for pines, with only the addition of a pit for bark, and a path, with barely head room to walk in; its similarity to this in every other respect has prevented me from making it part of the second number). The trees are planted on the outside, and admitted into the house, without disturbing the lie of the sashes, by means of a dovetail piece* in the wall plate, and over the groove, which is seen in the wall where the stem rests, of such a width as to accommodate its increase, without pinching, whatever time it may remain there. The chinks around it are to be filled with moss, to prevent the heat escaping.

A, plan, the furnace placed at the end to give a greater range to the flue, which is detached from the wall all round about two inches, and tied to it by a brick on edge, at every three or four feet distance.

B, elevation, the tree seen in the groove at the end; part of the longitudinal section shewing the return of the flue.

$\mathrm{C}$, end section, the gradual ascent of the flue from the furnace; and the door seen, for cleaning and ventilating the stove.

$\mathrm{D}$, centre section, the tree shewn on the treillage.

* Description of plate XXII. 


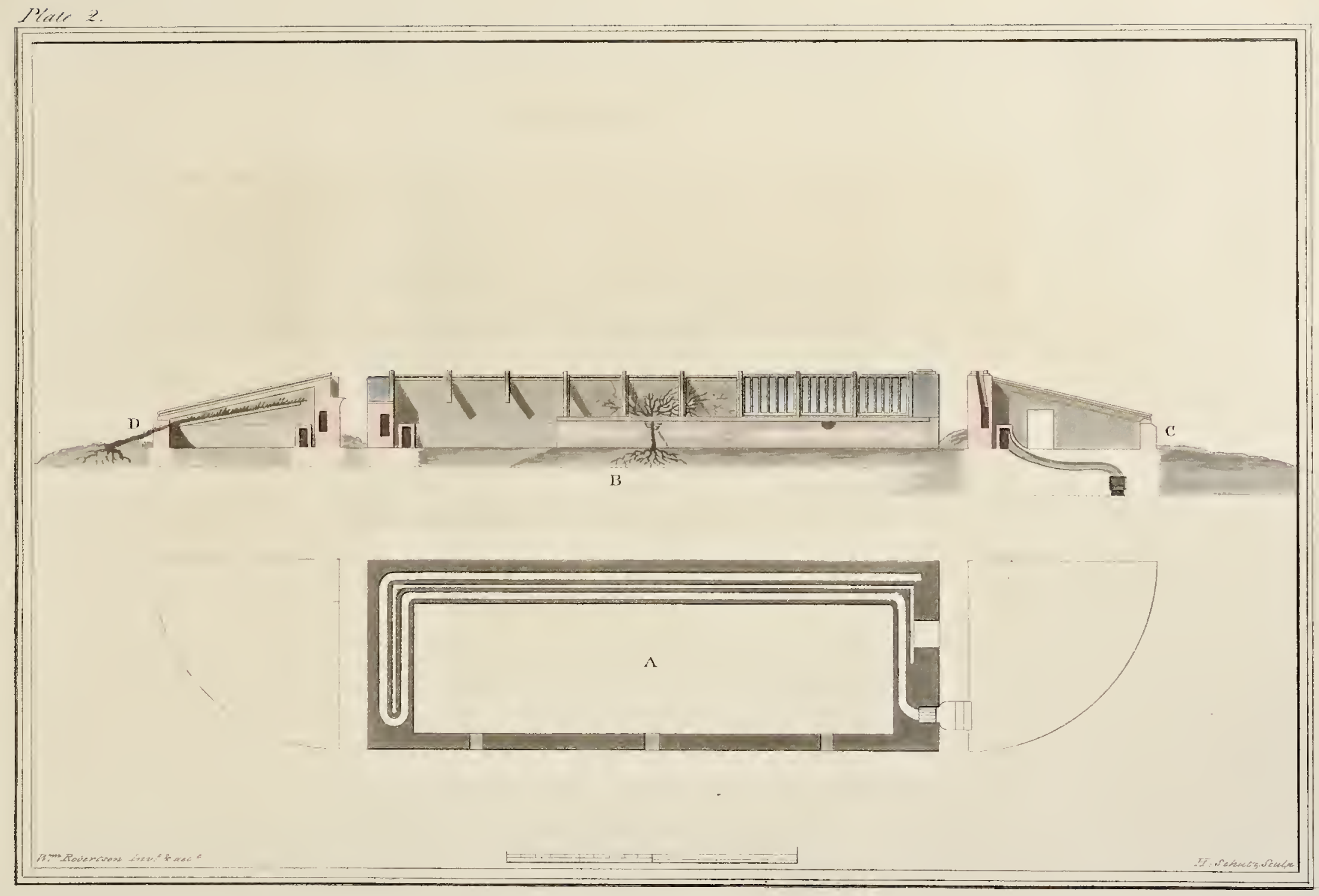




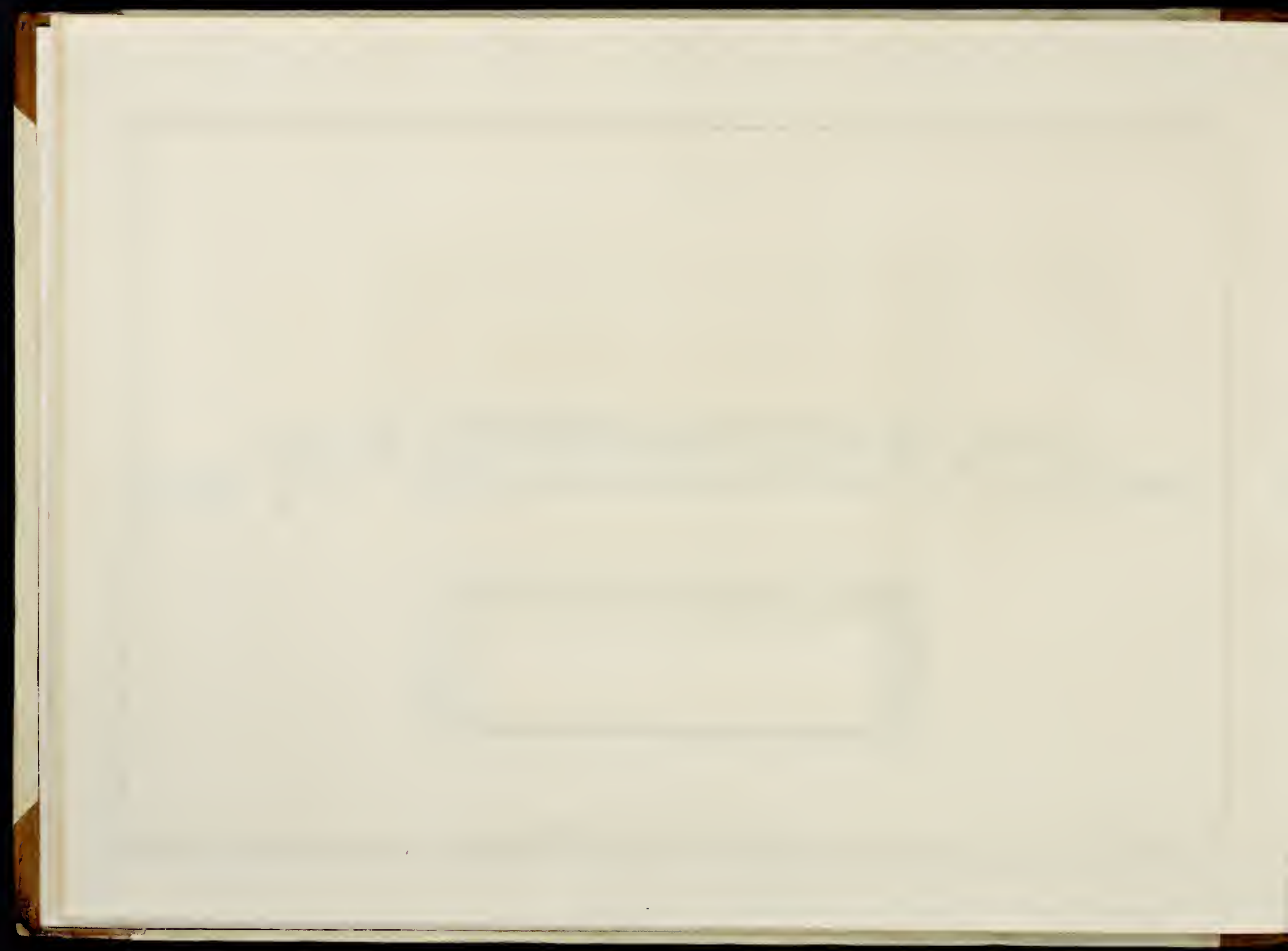




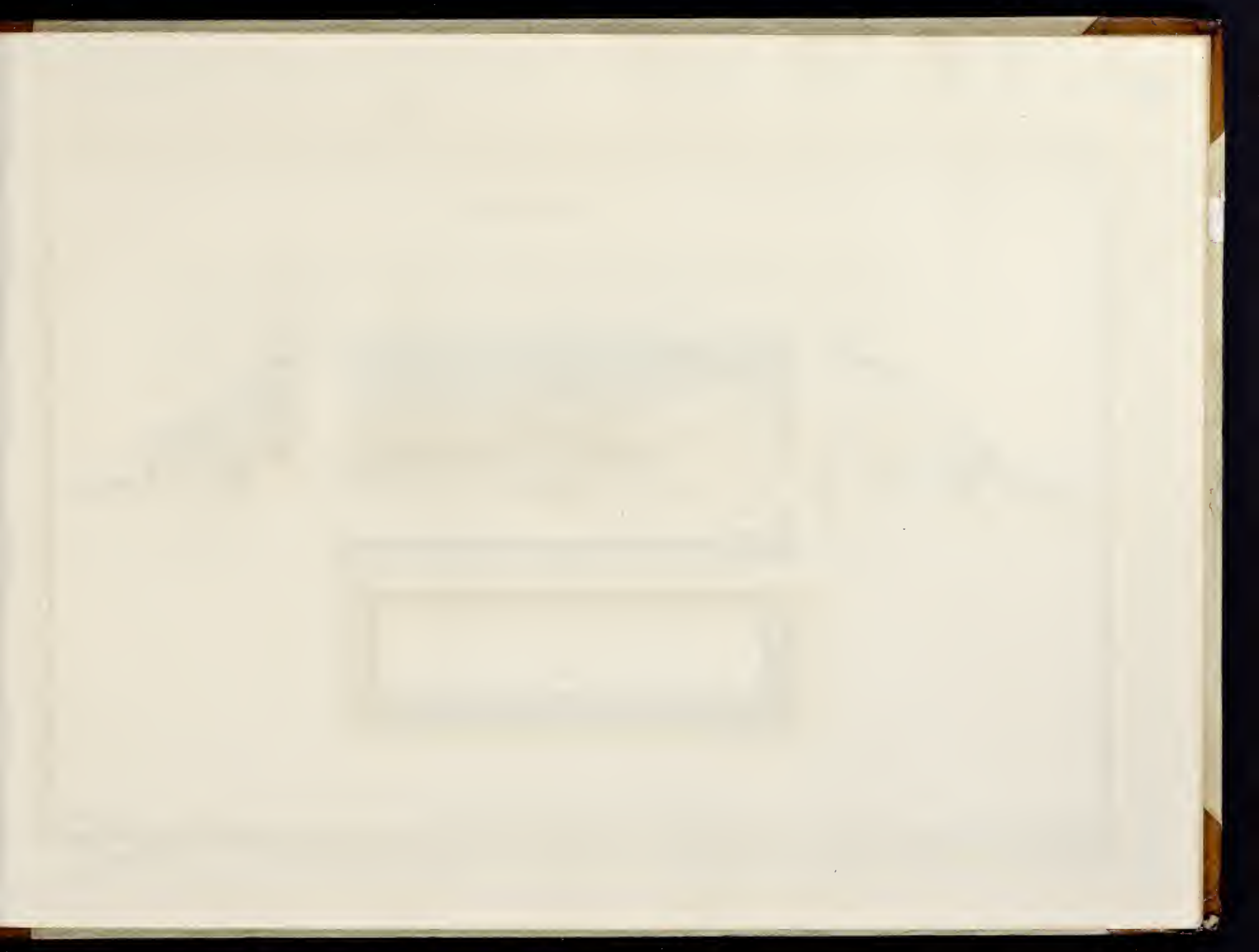




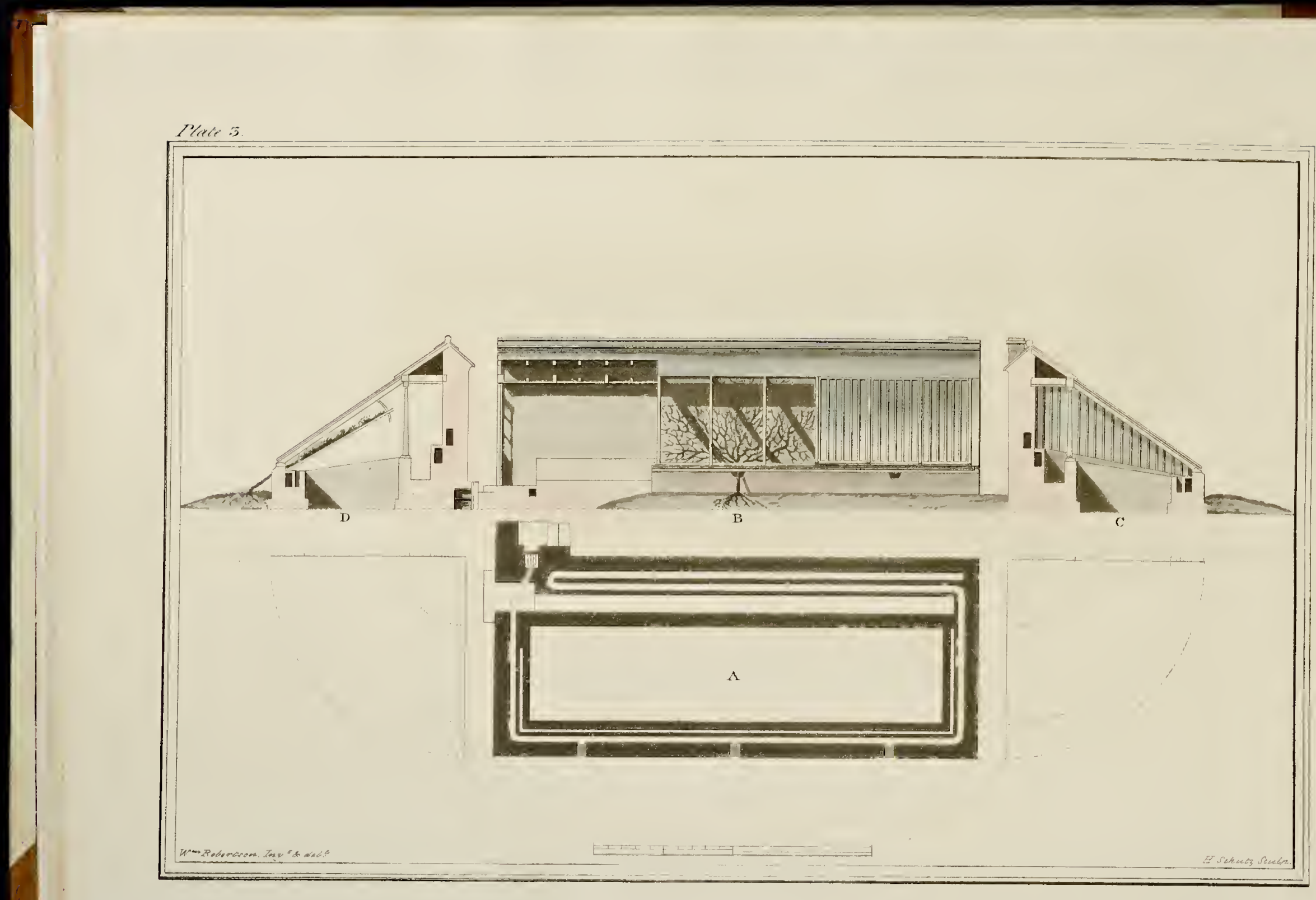




\section{PLATE III.}

A PEAcH Stove, forced with bark; and having also a furnace and flue, occasionally used at the discretion of the gardener, on the declining of the bark heat, or throughout. That part immediately over the back walk is shewn as slated for economy : here, where the trees are so near the glass, this will answer; but in pine stoves, \&c. where plants are always placed on the head of the back flue, it should not be used, that as much light as possible may be admitted; for the same reason, the ends should be always glazed. The head plate is supported by columns.

A, plan, in which is seen the bark pit, back walk, with the furnace, its flue surrounding the pit, and returning in the back wall.

B, elevation, with part of the sashes on, the tree admitted under the plate, and part of the length section through the path, and slating; where the construction of the roof is seen, the step in the path, and the neck of the flue, issuing from the furnace.

C, end section, where the depth of the bark pit is seen, the back walk, flues, columns, and ceiling joist.

D, end section, through the furnace, shewing the ascent of the flue, and the tree on its treillage. 


\section{PLATE IV.}

A РЕАсH Stove, different from any of the preceding, in its plan and elevation. A flue is carried through the centre of the house, returns close to the back wall, and again in the wall. The roof is of one continued slope to the wall plate. Trees are placed on the back wall, and on the sloping treillage in front, which is of such a length as not to shade the back trees. The sashes are divided into two lengths; the upper, but one third of the length of the whole slope, for the purpose of giving air with greater facility.

A, the plan, where is seen the furnace, flue, and arches. The angles in the bends of the flues in this and the Vth Plate are shewn as an error to be avoided.

$B$, elevation, shews part with the sashes on, and their division, the flue and trees in both front and rear.

$\mathrm{C}$, end section, with the furnace, and flue passing through the house and returning in the back wall; also the coping of the back wall.

$\mathrm{D}$, end section, with the flue seen distinctly; the door, and passing of the smoke. 


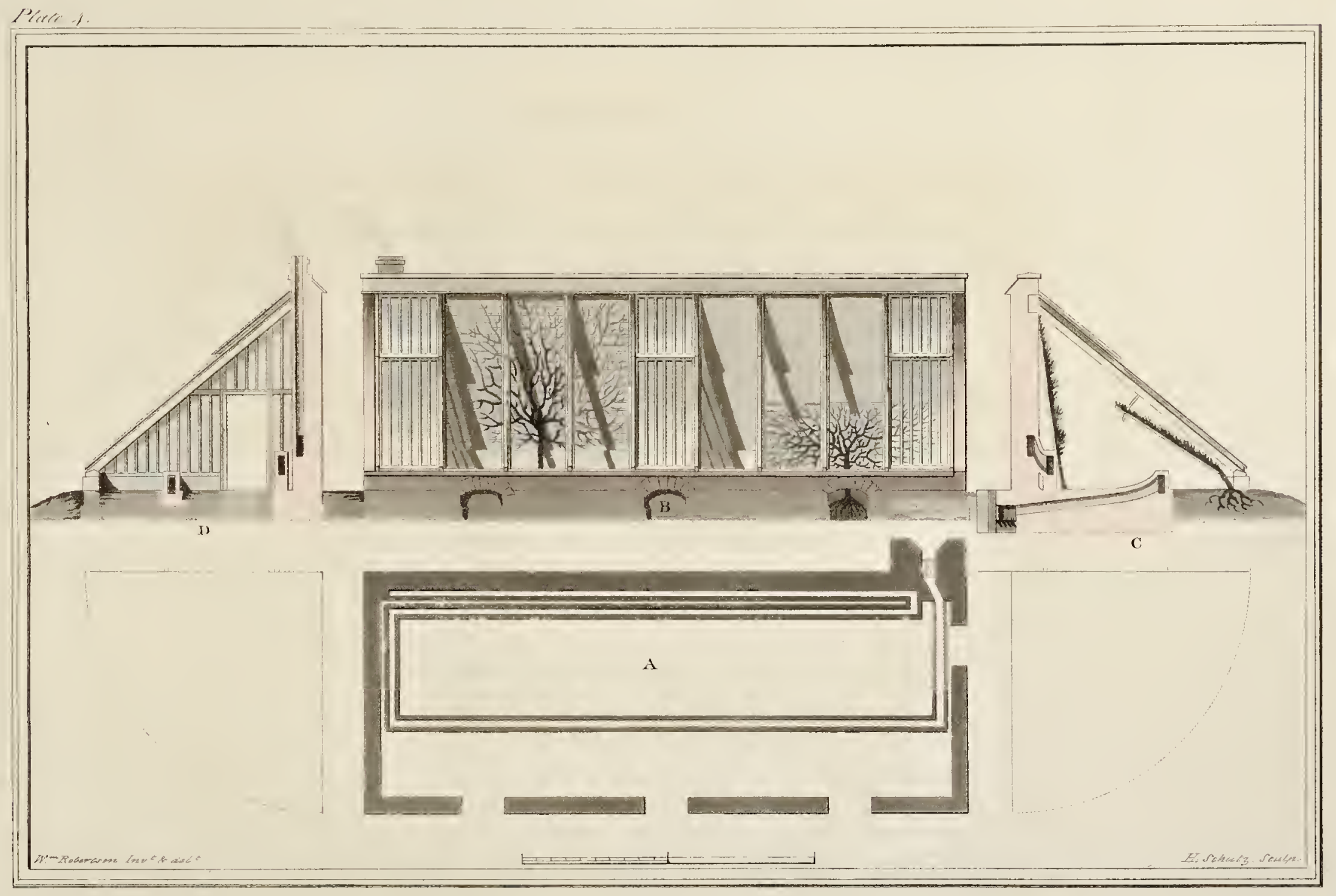




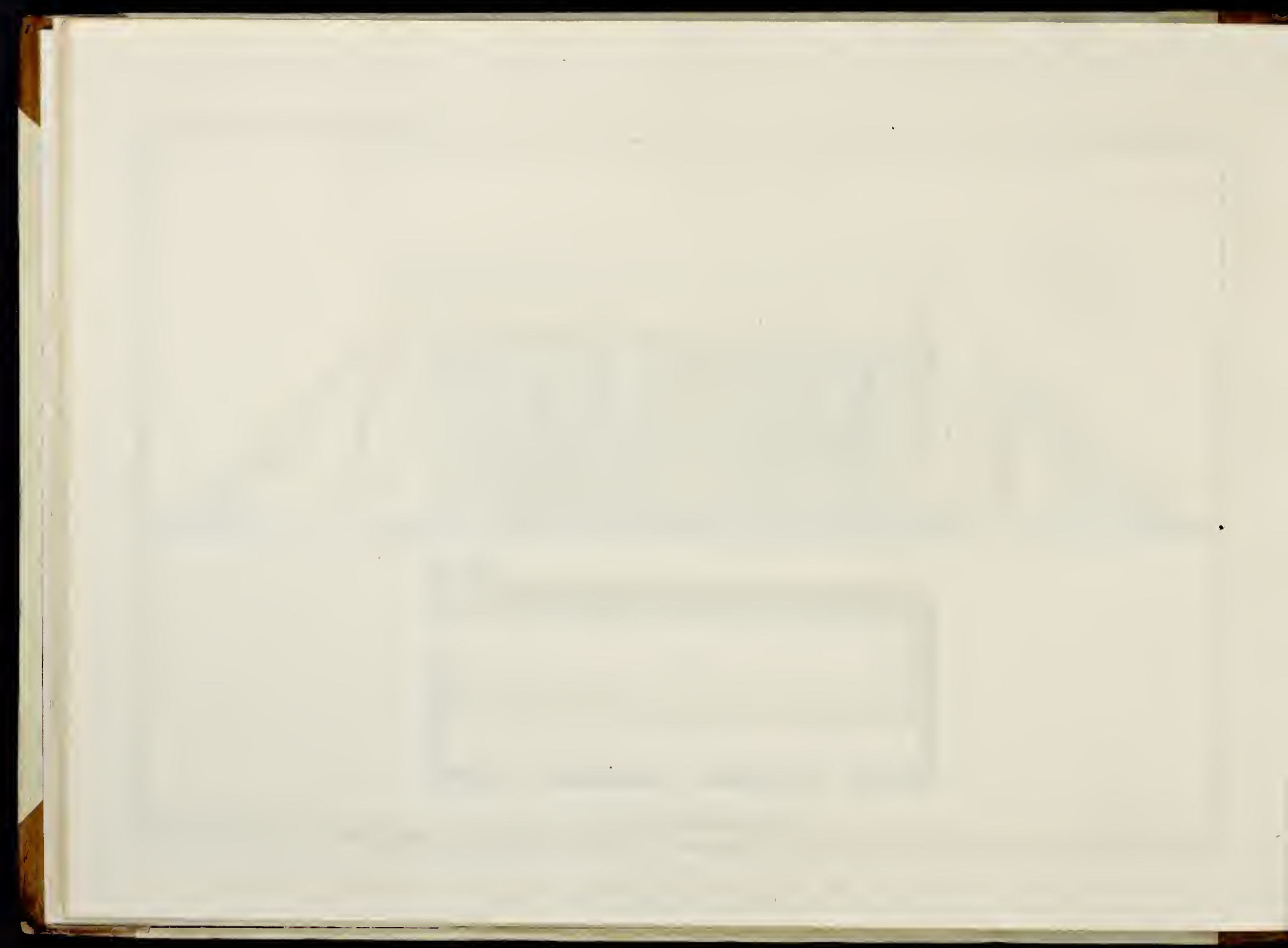




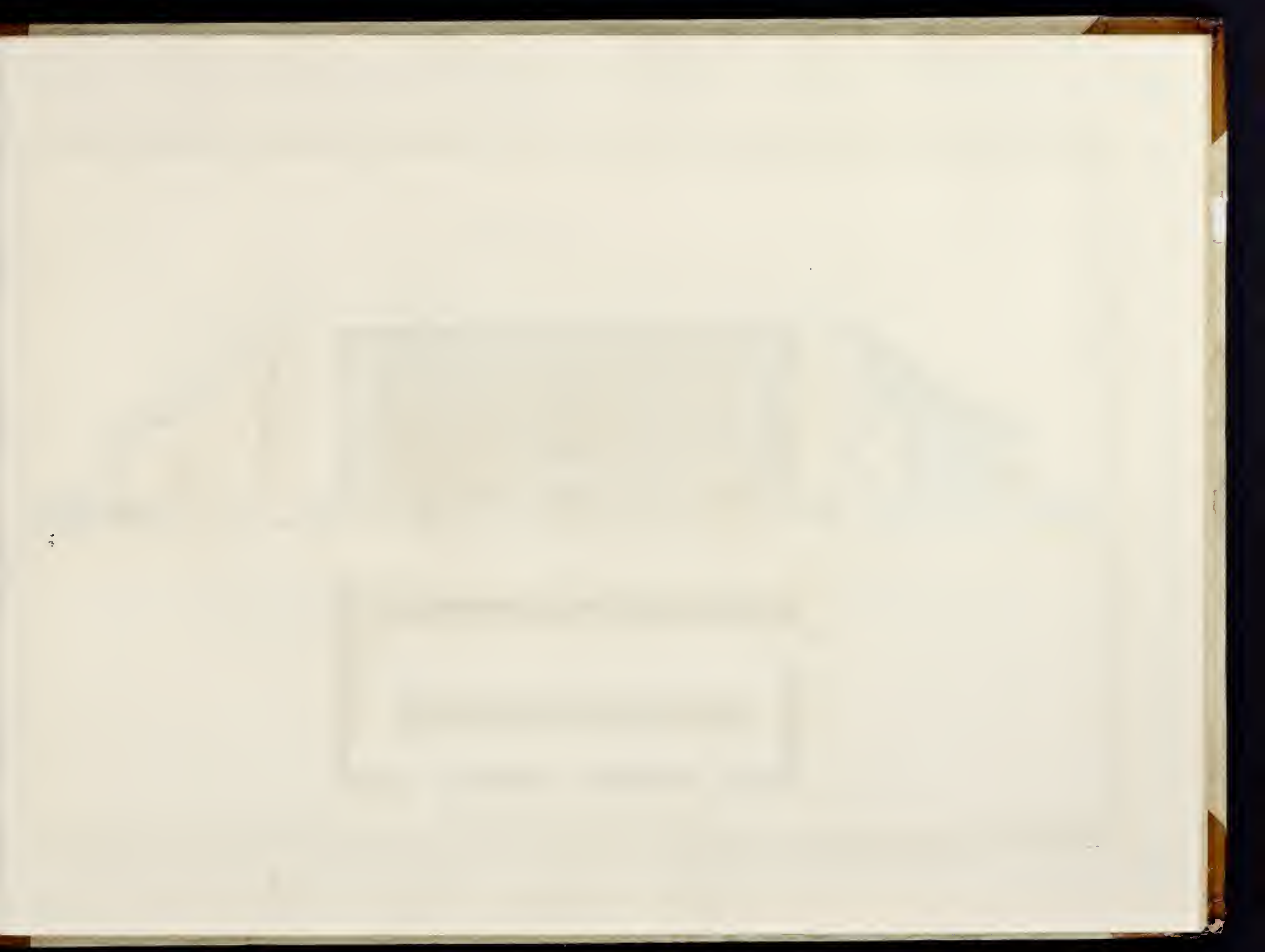




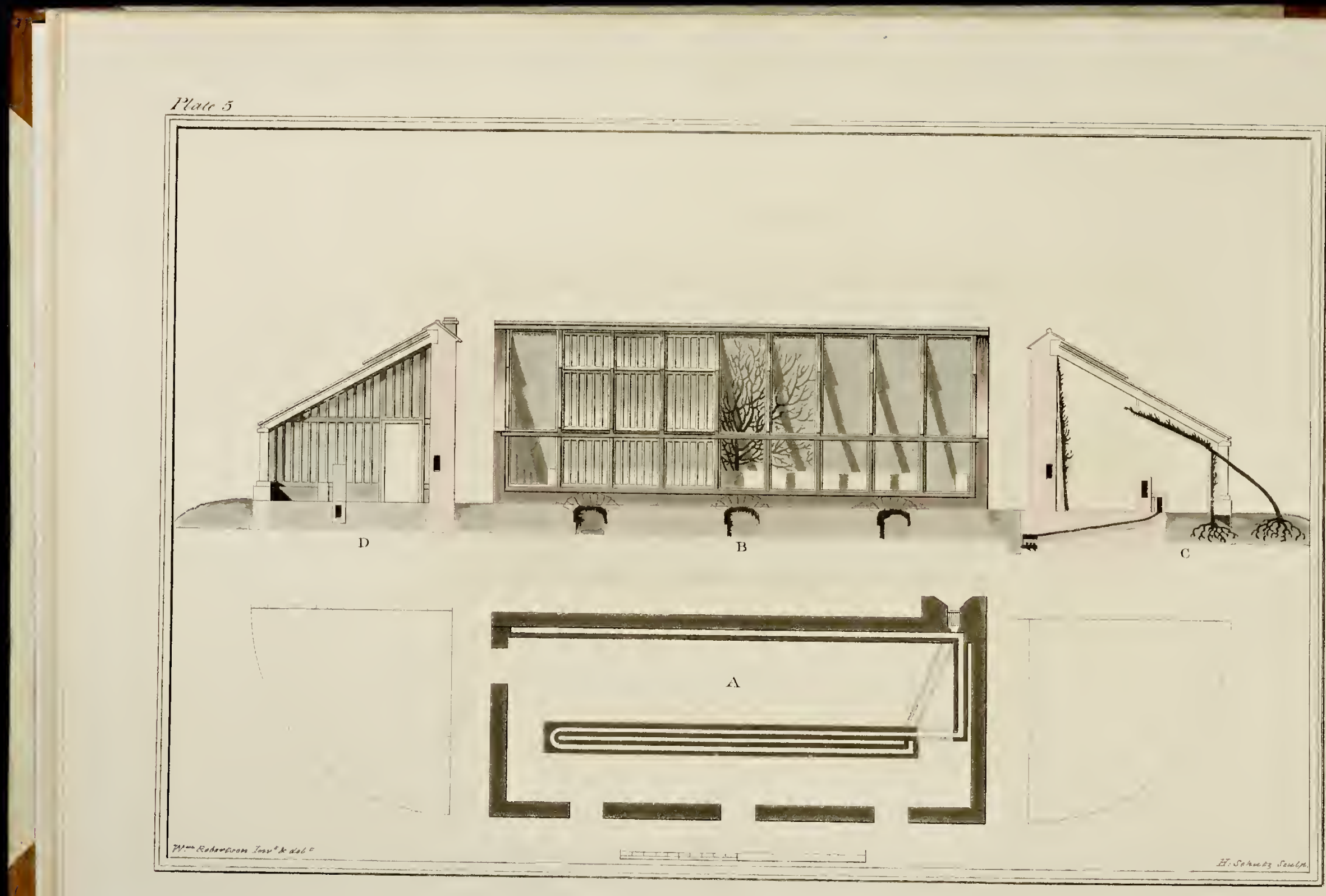




\section{PLATE V.}

THE most complicated form of a Peach Stove. The flue issues from the furnace, rises about midway of the breadth of the house, runs nearly its length; but returns close to the first range, and by dipping, or bending downwards, as seen in the end section of the large Fruiting House, Plate IX. and fig. G. Plate XXIII. leaves room for a path (which the height of the second return makes necessary, to prevent the flues being broken by climbing over them), and then rises and returus in the back wall. By this disposition is intended, that the whole of the fire heat should be communicated to the air in the centre of the house; and that its area should be divided into two distinct borders: that next the front the narrowest, as the roots of its trees can run into the outside one. A third set (standards), may be trained on the sloping treillage, as represented, by making the outside border of sufficient breadth, when this disposition is adopted.

A, the plan; shews the furnace and disposition of the flues, the dips expressed by dotted lines.

$\mathrm{B}$, elevation; shewing the division of the slope glasses, the arches in front, and the passages at each end.

$\mathrm{C}$, end section; where is seen the three different dispositions of the trees; with the flue running from the furnace into the first range, the difference of the level of the second, and the height of the third, in the back wall.

$\mathrm{D}$, end section; where the flues are distinctly shewn, and the dip of the second range. 


\section{PLATE VI.}

A smali. Pine Stove, worked by one fire; the flue runs along the ends and front of the house into the back wall, above the level of the top of the bark pit, and returns again in it. That part of the wall which is seen to project in the section $\mathrm{C}$, is intended for footing to stand on, when the pines are adjusting, or the grapes thinning. The vines are planted inside, and communicate with the outside border, as the peach trees; but the voids are obliged to be much more numerous (as a vine is generally planted to each rafter), and are either arched, or have a strong flag laid over them, which answers as well, and is less troublesome.

A, the plan; shewing the flue passing from the furnace, the walk surrounding three sides of the pit; in the front wall of the pit are seen the grooves to admit the stems of the vines, and prevent their being injured, by the rubbing of passengers against them.

$B$, elevation; divided into three parts, the centre covered with its slope and front sashes; the end next section D, shews the pit, with the grooves in its front, and columus supporting the rafters, by a section through the front path.

$\mathrm{C}$, section, through the centre of the house, shews the plants in the bark, a vine trained to the rafters, the flue and projection in the back wall to stand on.

$\mathrm{D}$, end section; the furnace, and flue ascending from it seen, also the door and inclined descent of the path from it to the front. 


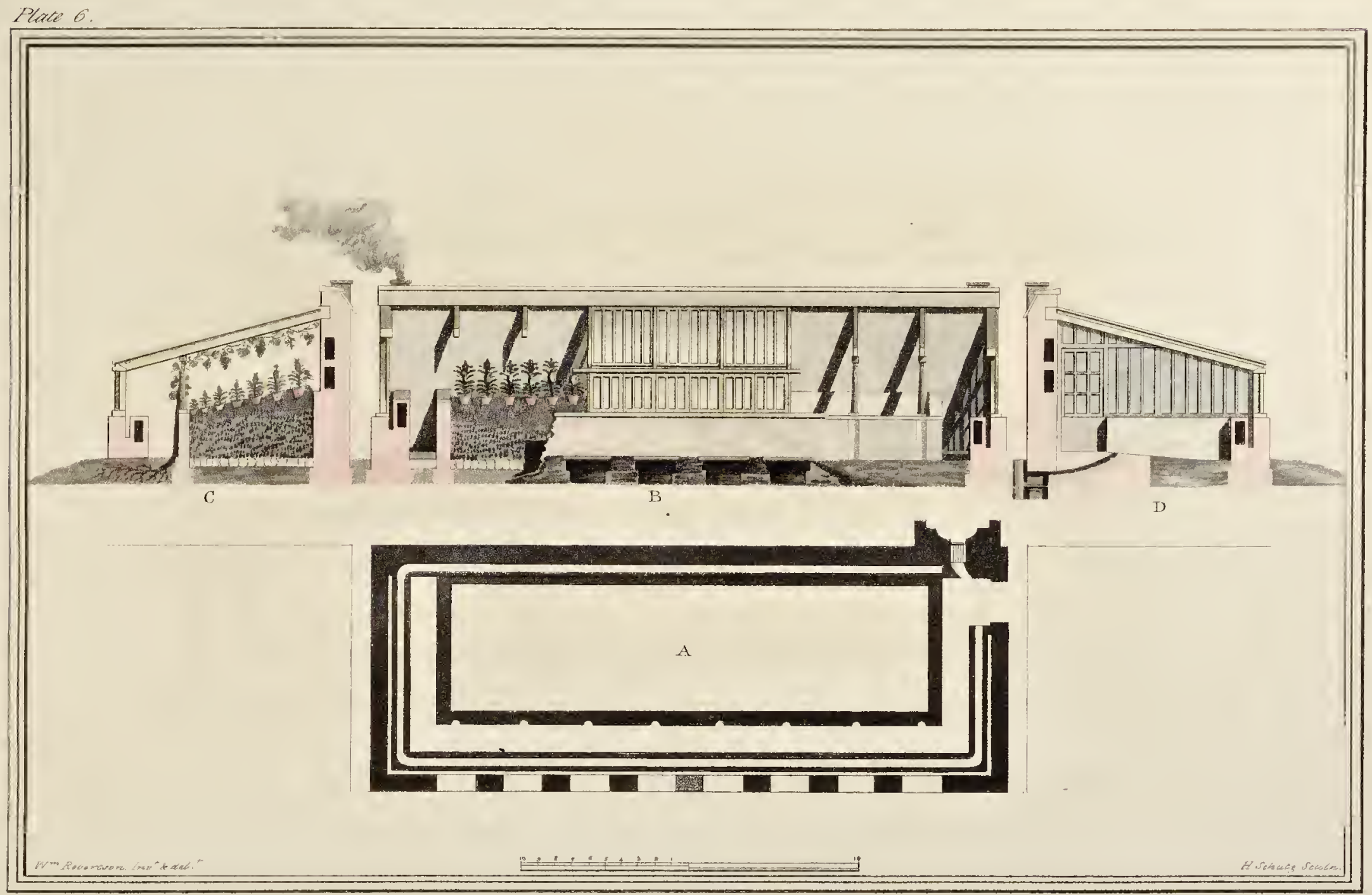




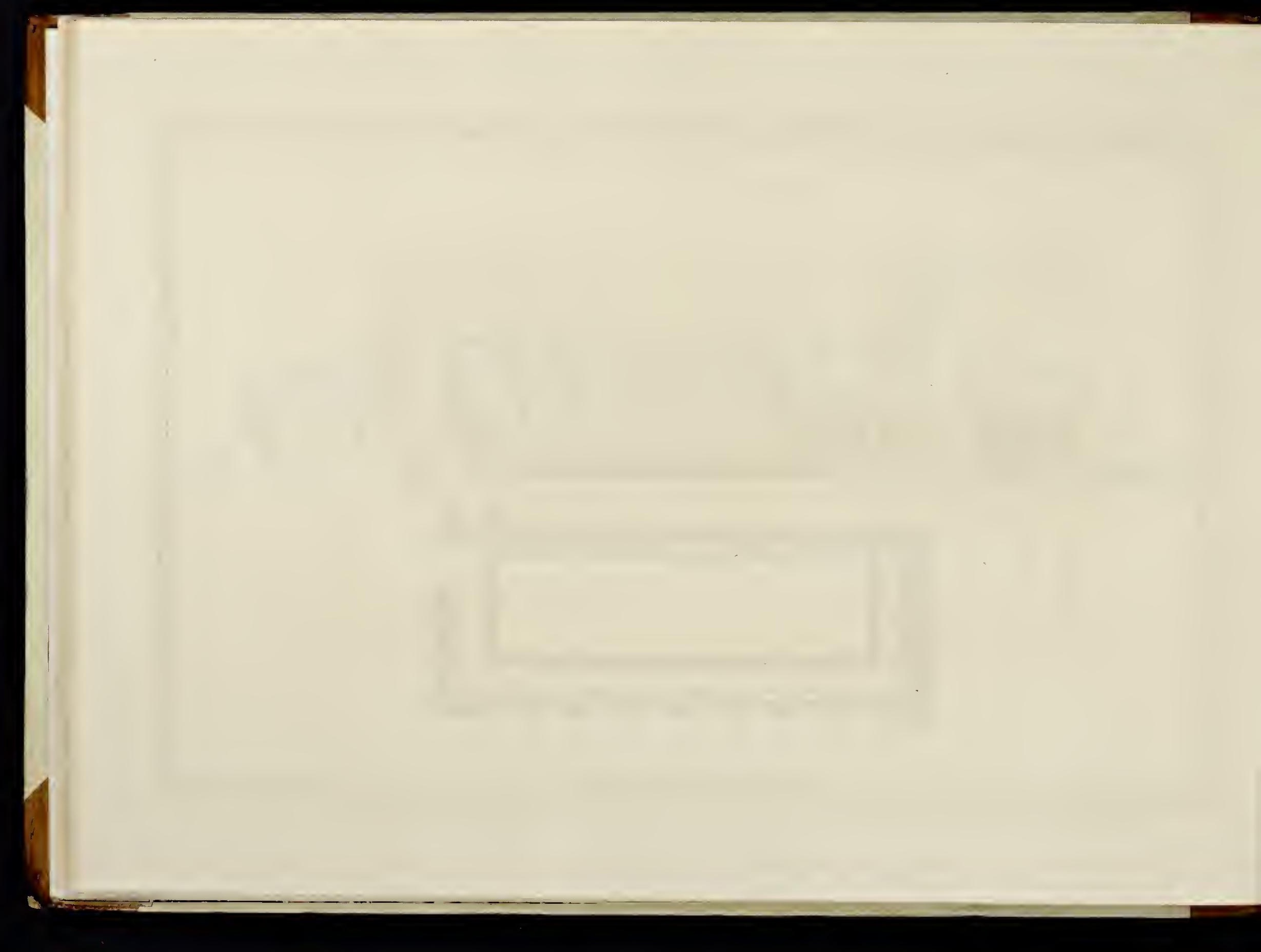




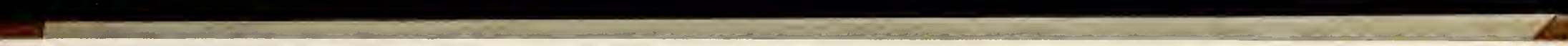




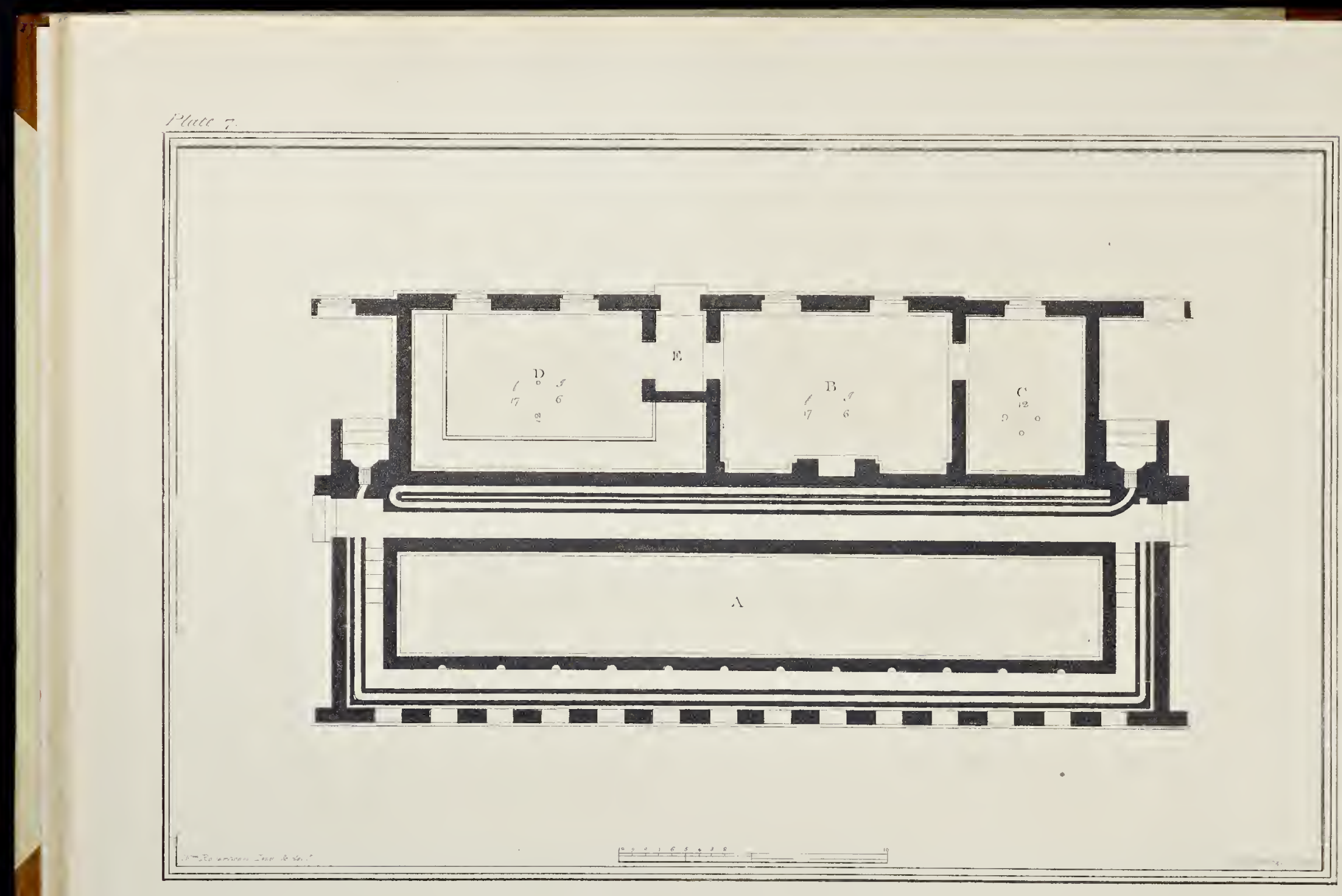




\section{PLATE VII.}

Ground Plan of a Fruiting Pine Stove, sixty feet in length, and worked by two fires. The flue from one runs round the front, dips under the entrance, and goes into the back wall without returning; but lest the heat should not be sufficiently expended in that length, a damper* is placed in the funnel, so high on the outside, as to be reached from the ground, which, by being closed when the heavy smoke is past, will prevent the heated air from escaping in any degree, by its being more or less closed. That from the othcr, runs along the back walk (nearly on a level with it), returns perpendicularly over this first, both being detached from the back wall, and then into it. At the back of the stove, is the gardener's apartments, consisting of a sitting room and bed chamber; to these is added a store room, for seeds, flower roots, and the temporary rcception of ripe, valuable fruit, such as pines, grapes, peaches, \&c. therefore must necessarily be placed under his eye; this is separatcd by a passage from the other rooms. The funnel from the fire in the sitting room, docs not communicate with the flues of the stove.

$A$, the bark pit; the path seen surrounding it, and the steps for descending to the front part.

$\mathrm{B}$, the sitting room. C, bed chamber. D, the store room, and $\mathrm{E}$, the passage. 


\section{PLATE VIII.}

Fievation of the plan in Plate VII. and the plan compressed, for the purpose of shewing how the oblique sections of the internal parts are drawn. Besides that part shewn as covered in, there are four sections through differcnt parts of the house seen in this Plate, by which cvery part of its formation worth shewing in a length section, is secn, and made plain to any capacity. The upper sashes, are one third of the length of the whole slope, and the vines are planted inside.

$A$, is the portion covered in; at each end of the front wall, are seen oblique sections of it, its flue, and path.

$B$, shews thc section of the back fluc, over the furnace (and the neck of the othcr flue, just entering the back wall, its ascent marked by pricked lines, in which the damper is placed). In the other cnd section the revolution of the same flue is seen; its entrance into the back wall, is seen over $\mathrm{B}$, and the pricked lines mark its course.

$\mathrm{C}$, shews the back wall of the pit, with its columns, and an oblique section shewing the path.

$\mathrm{D}$, shews the plants in the pit, its front wall, with columns and grooves.

At $\mathrm{E}$, is shewn an oblique section of the pit; the manner of drawing it is seen from the line marked 1-2- under it in the plan, by drawing up perpendiculars from the respective lines it intersects, as the two seen from each extremity. 


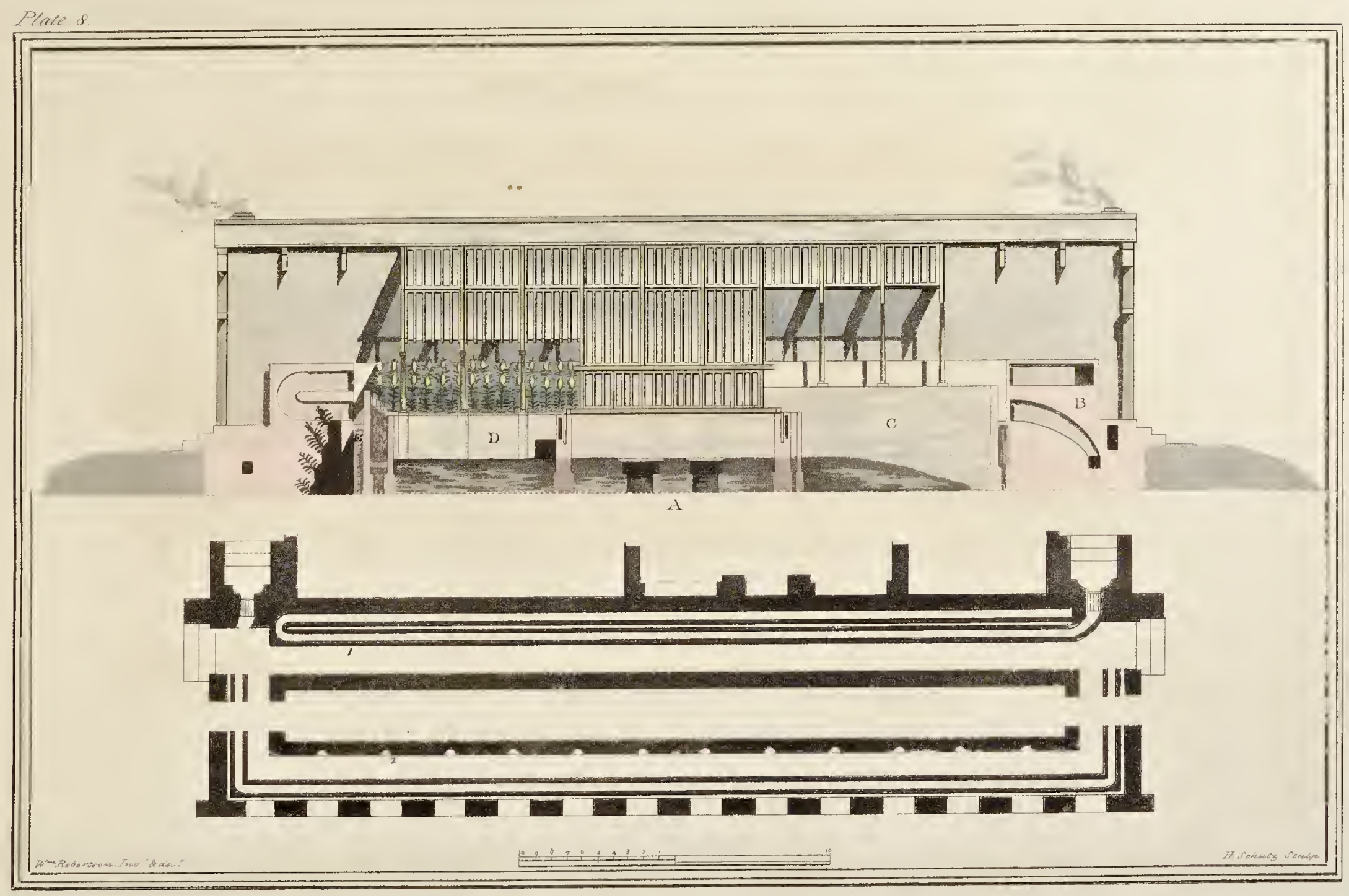




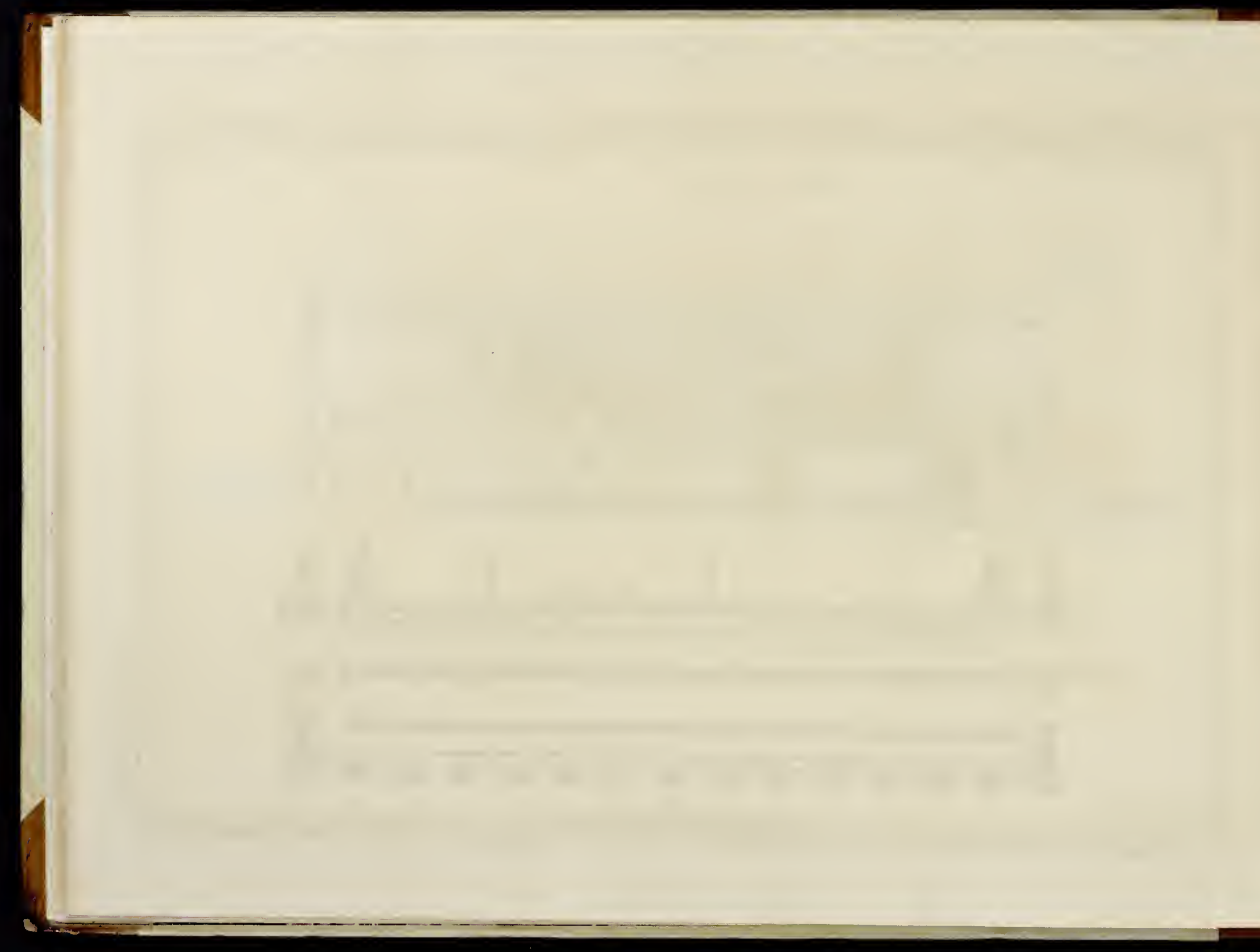





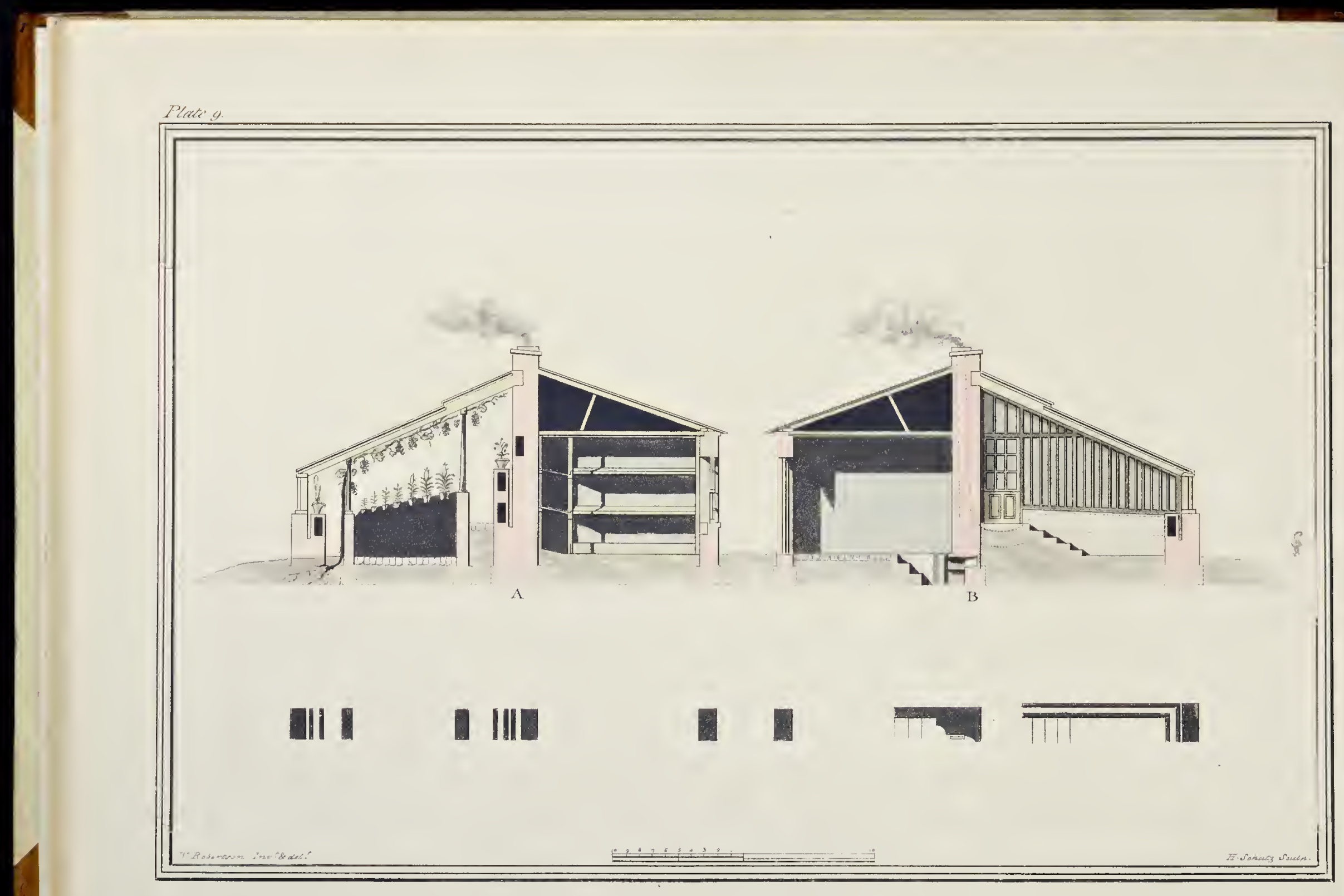




\section{PLATE IX.}

Conrains two transverse sections, through the Shed and Stove. That at A, is through the store room, (seen furnished with shelves for flower roots, \&c.) and that part of the stove opposite to it, in which is seen the difference of the levels between the back and front walk; theformer being raised for the purpose of giving a full view of the pit, and all the house; as nothing can liave a worse effect than having it low, for all view is then limited to looking straight forward or upward; and the house, though ever so well formed and furnished, is seen to great disadvantage. The columns are seen on the front, and back wall of the pit; and are necessary, as well for beauty as utility, in all large stoves of this description.

$\mathrm{B}$, section, through both stove and shed, the depth of the furnace and descent to it seen, in the shed. In the stove, the steps from the back, to the front walk are seen. The dip of the front flue under the entrance, and its ascent in the back wall, marked by dotted lines.

$\mathrm{N}$. B. This dip is what was referred to in the explanation of Plate $\mathrm{V}$. 


\section{PLATE X.}

$T_{H E}$ elcvation of the back front of the gardener's apartments, and the sections of the different rooms. Their floors are raised six inches above the level of the ground; those of the sitting room and bed chamber, to be boarded; that of the store room paved with brick, and the roof to be slated.

A, elevation,

$\mathrm{B}$, section.

$\mathrm{C}$, bed chamber, nine feet broad by twelve in length.

D, sitting room; twelve feet by seventeen fcet six inches, recesscs at each side of the chimney for cupboards, \&c.

$\mathrm{E}$, entry, four feet wide.

$\mathrm{F}$, store room, twelve feet by seventeen feet six, with the shelves for flower roots, $8 \times \mathrm{c}$. 


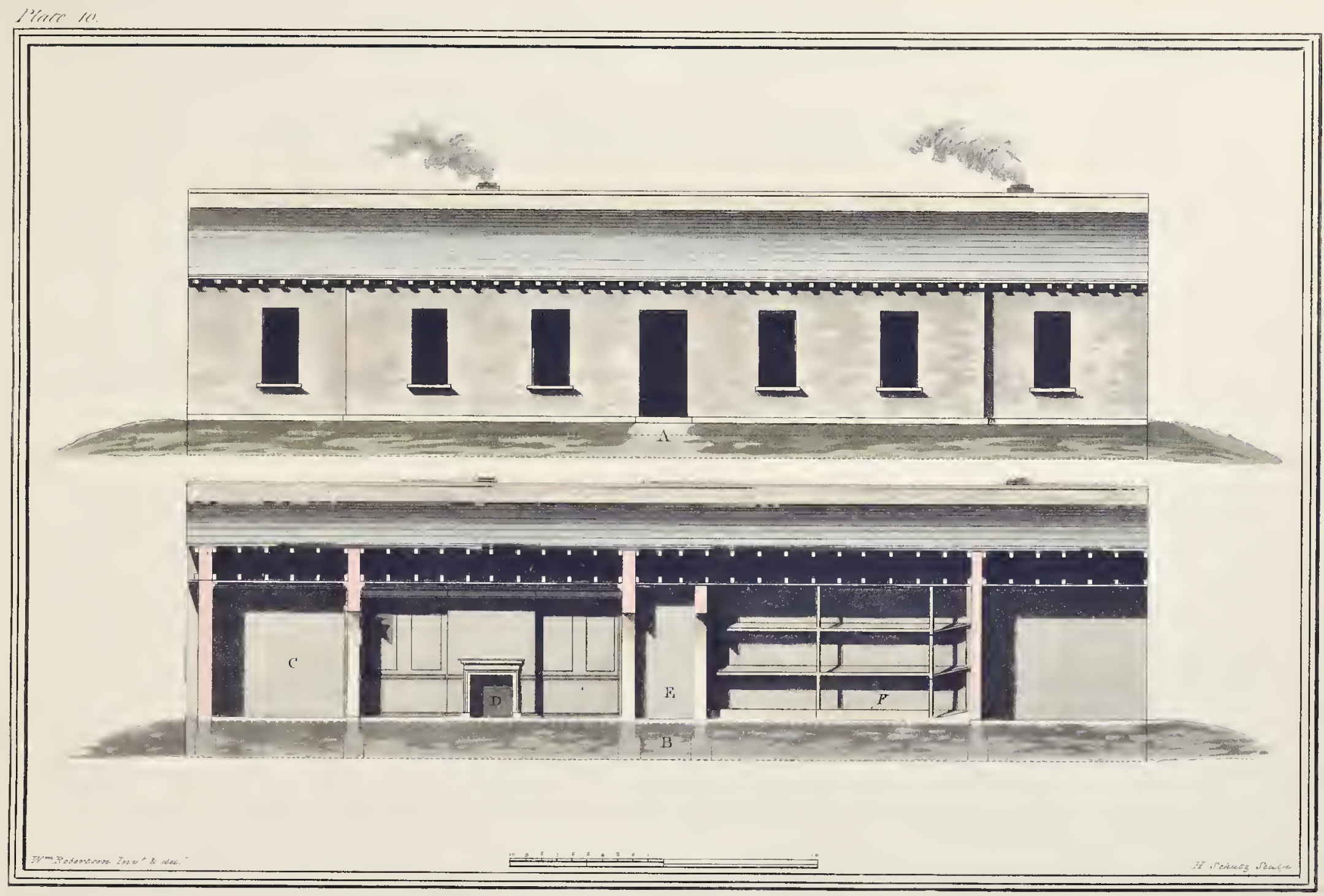




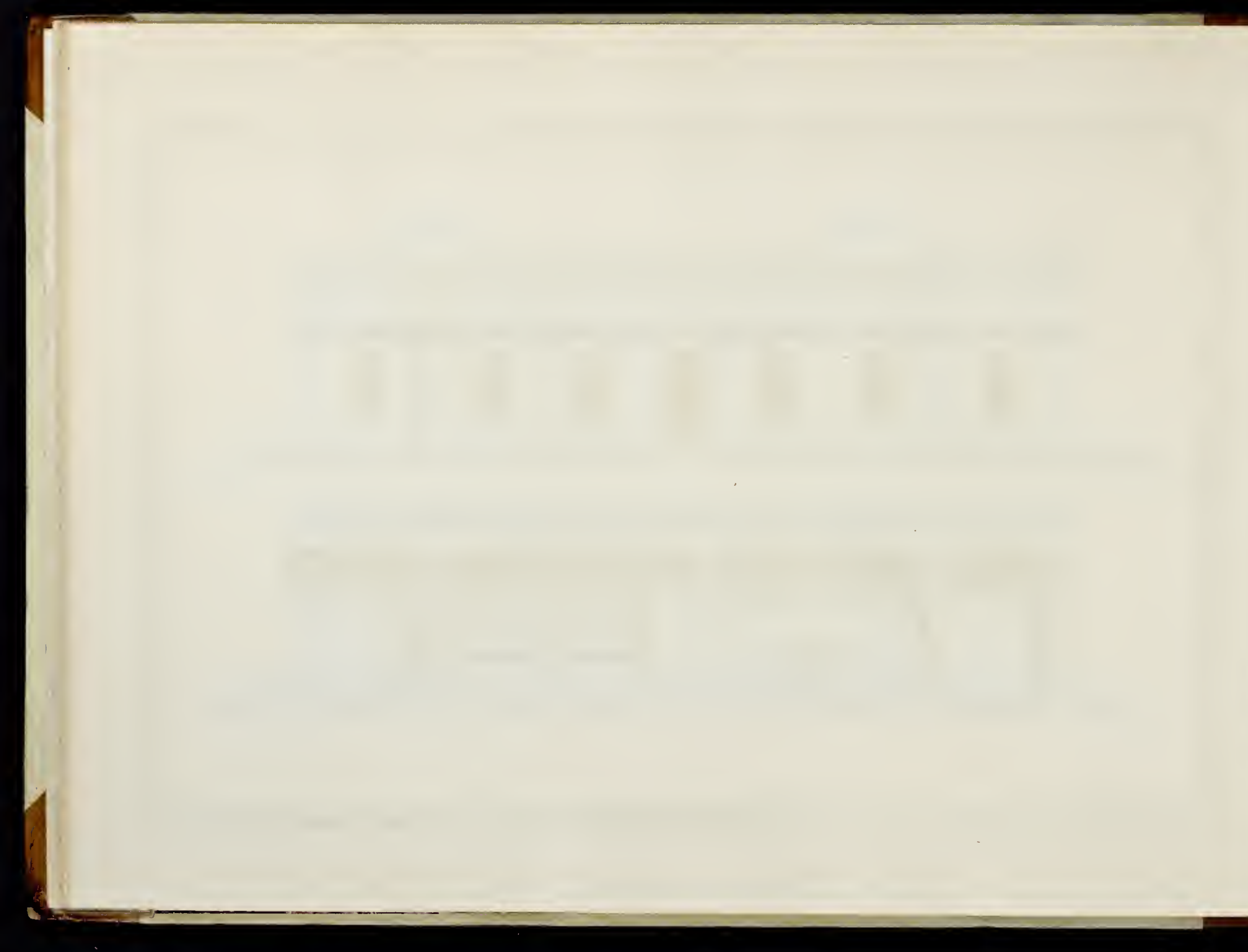




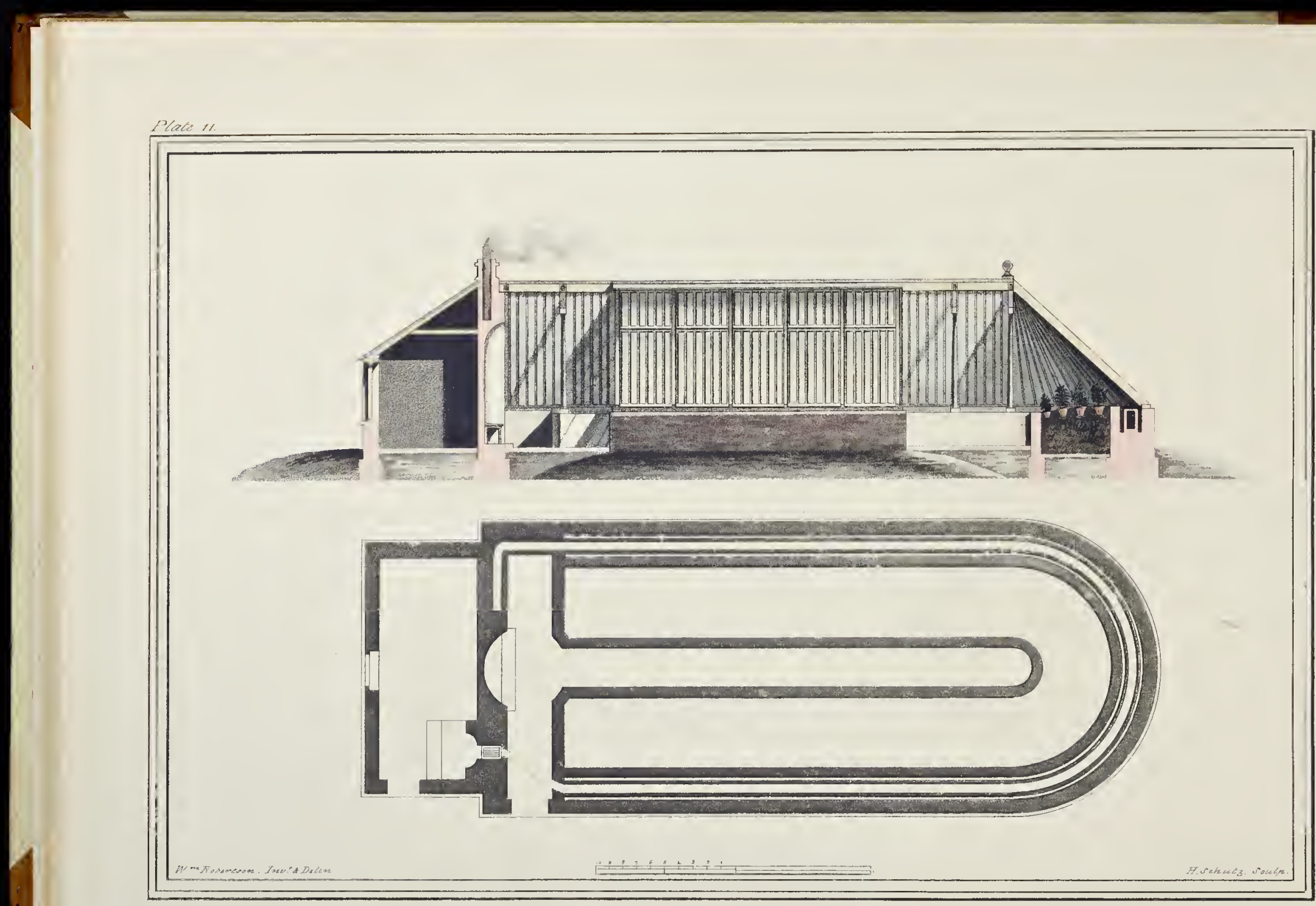




\section{PLATE XI.}

A Stove intended for tender Exotics, the plan, part of the elevation, and longitudinal section shewn; the roof is pointed, and glazed on both sides, that on the west side only having moveable sashes, the circular glazed end is placed directly south. The rafters are morticed into the ridge plate, and are supported by columns on the pit wall, morticed into themselves. When these are thought not sufficient to prevent the roof from spreading, either, or both of the following methods, may be uscd. An iron bar three quarters or one inch diameter, flatted at both ends, should be let into each pair of rafters, above the heads of the columns, and pinned through (as seen in the roof, fig. B, Plate XXIII.), or studs may be brought up in the wall, the plate morticed upon them, and the rafters shouldered upon that, will effectually secure them. Opposite the path a niche is seen, with a seat in it. If vines are introduced from the outside, and trained from the rafters, round the bars, they will prevent them from appearing unsightly. 


\section{PLATE XII.}

Contains the elevation of the circular end of the last Stove, and the transverse section of the same end. The entrance is seen on the side of the elevation; in the section the disposition of the internal parts is shewn, being drawn up from the plan under it, as the elevation is from the same, inverted: the position of these stoves (in respect to their length) is north and south. This disposition would have been more perfect if the path had been carried round the pit, as in Plate XV. and would then receive large plants; the centre path should also be contracted, when the stove is erected solely for use. 

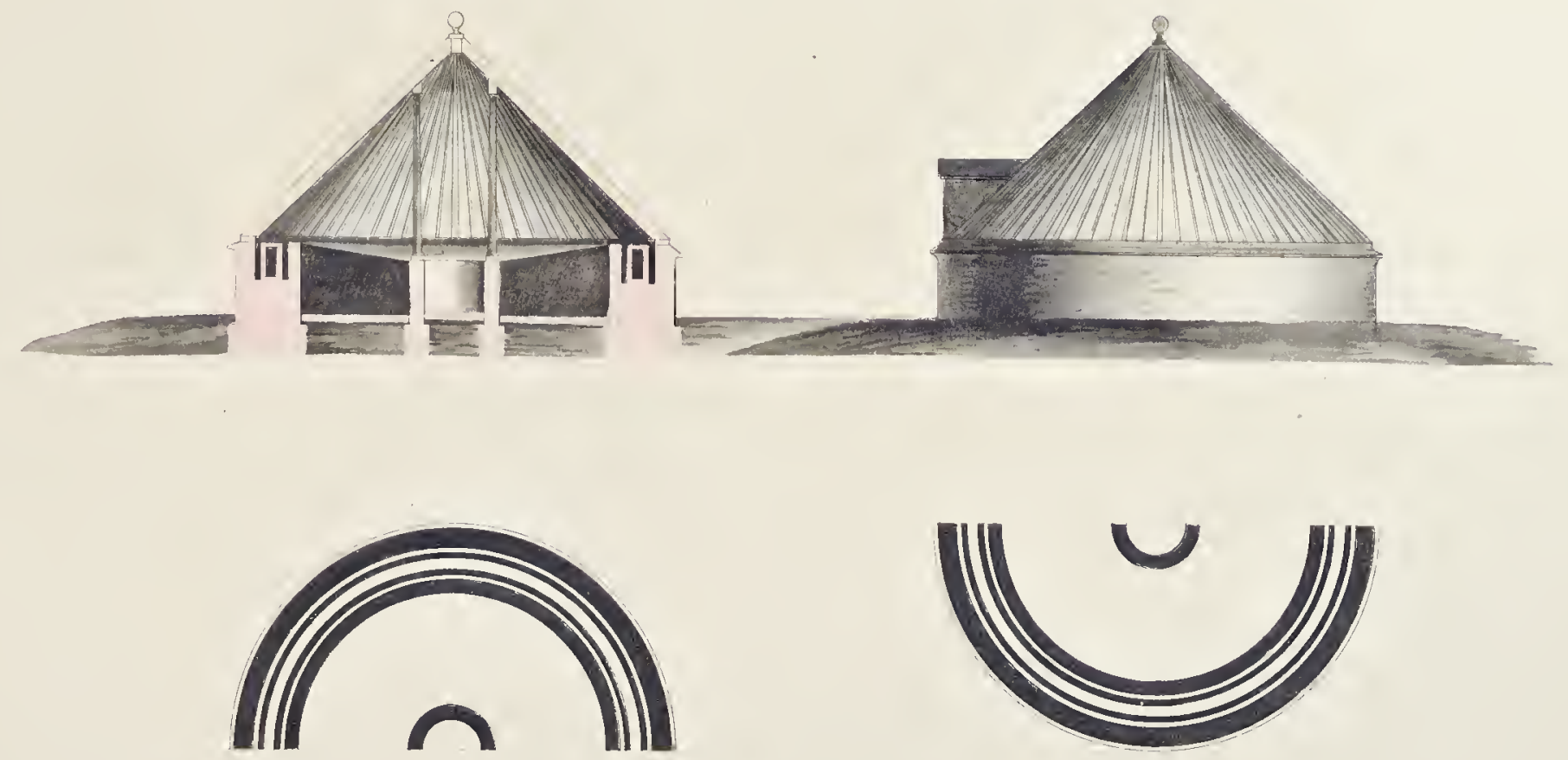


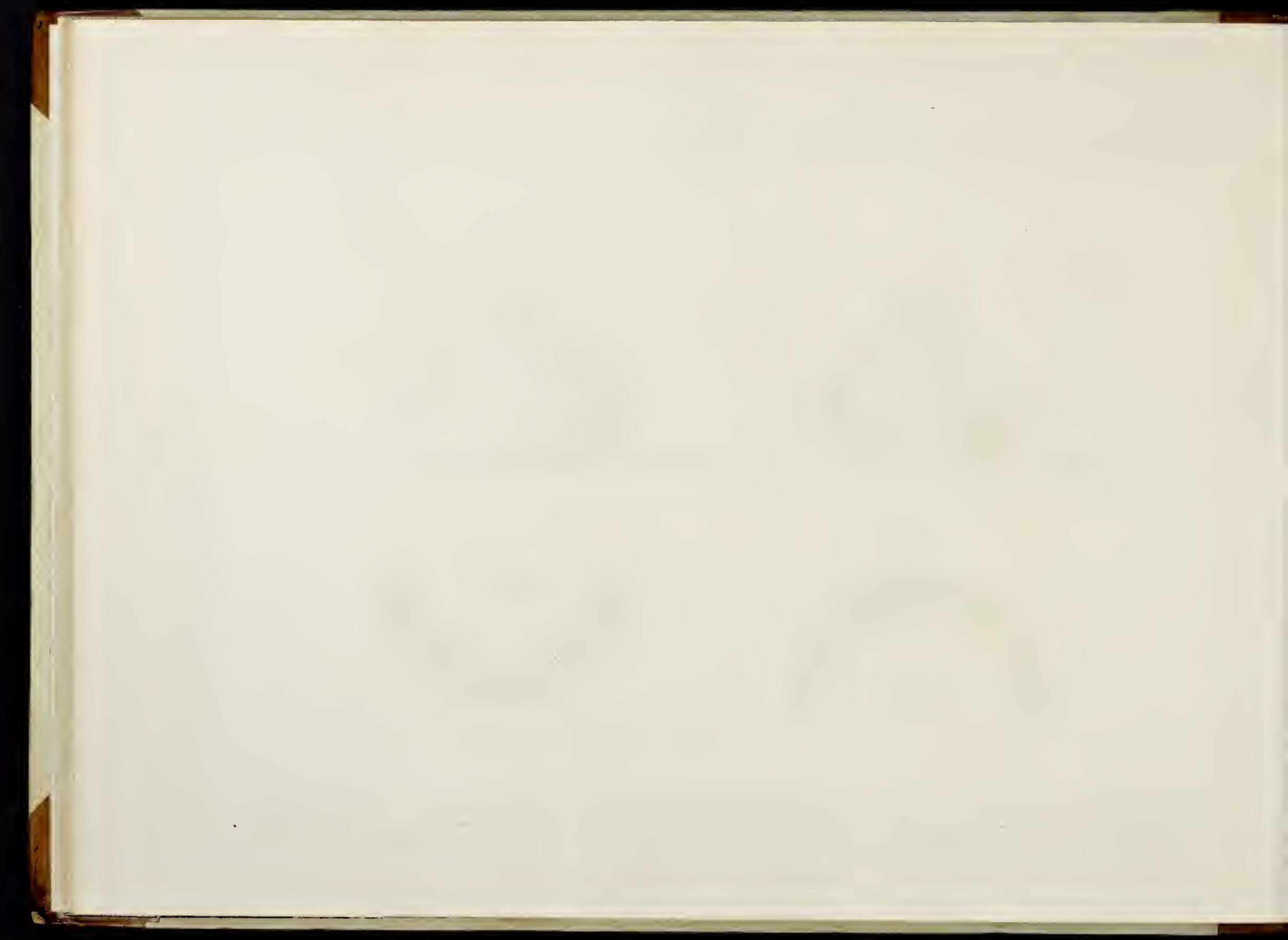




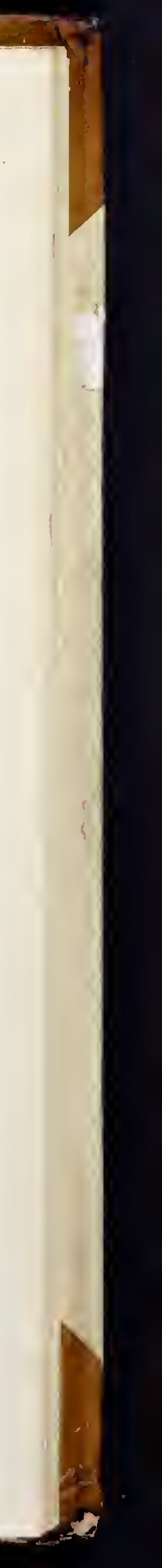




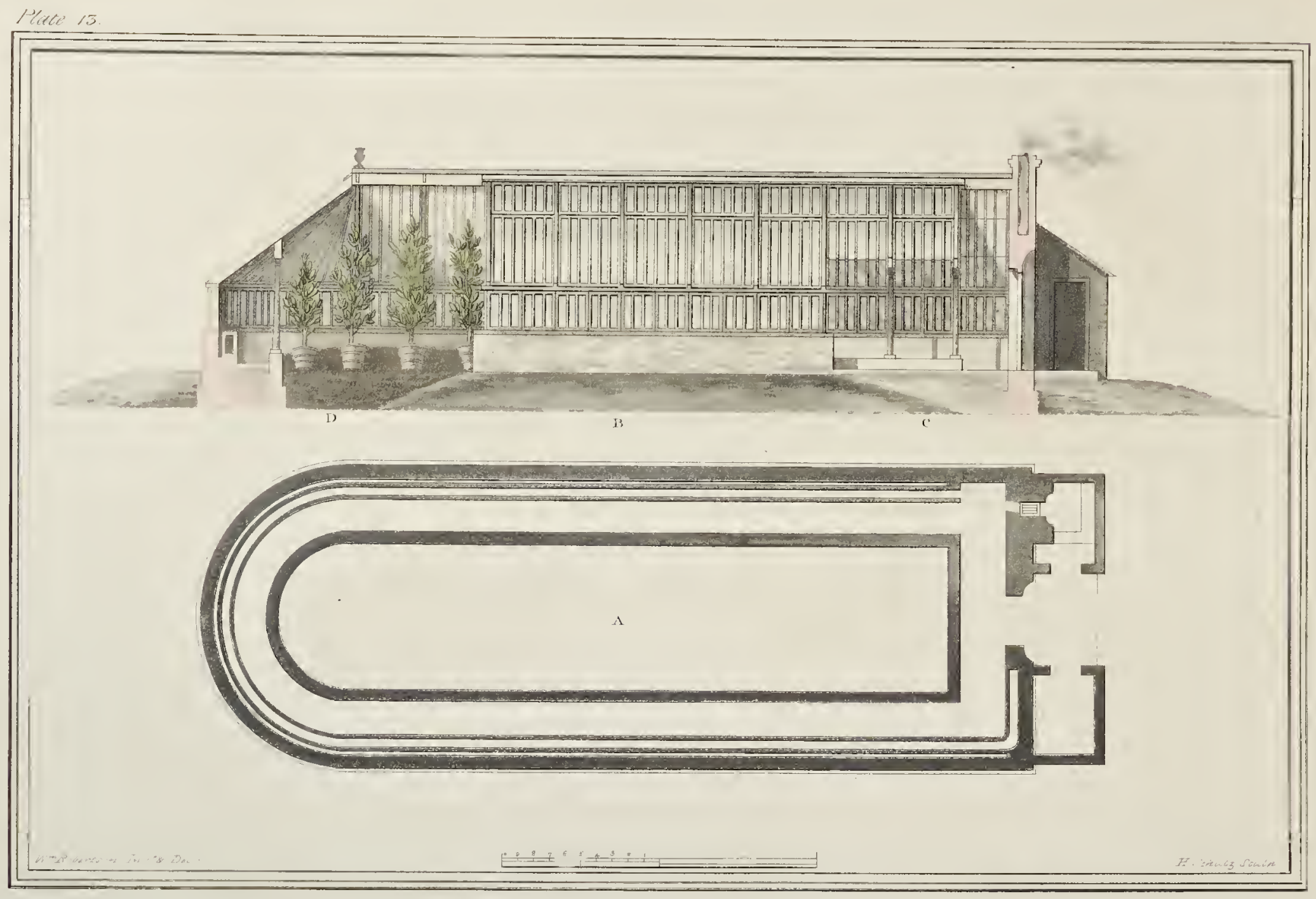




\section{PLATE XIII.}

THE Plan, elevation, and two sections of a Stove for forcing Cherry-trees, with bark and fire heat. The pit is placed in the centre, surrounded by the flue and walk; is sunk two feet nine inches below the level of this last, and rises nine inches above it ; on this account it will receive the largest trees used for this purpose, particularly in the middle row. The perpendicular sashes raise the front so as to give head room for walking round the pit; and the slope rafters are supported by columns on the pit wall.

A, Plan, the flue and walk seen surrounding the pit; and the entrance in the back wall between the two small sheds.

$\mathrm{B}$, part of the elevation on the side.

$\mathrm{C}$, section through the front walk; shewing the height of the pit wall above it.

D, section through the centre of the house and pit; shewing the flue, walk, pit wall, with the columns on it, and the bark bed, with the trees in their tubs plunged in it, and the framing of the roof, \&c. at the other end the flue is seen as it winds over the door before it goes out. 


\section{PLATE XIV.}

THE Elevation of the circular cnd of the Cherry House in the preceding Plate; and a transverse section, shewing its internal disposition. When forced with fire alone, the trees are planted in a prepared compost, or the tubs plunged in the common mould. The places of the timbers on the circular part are found, by first marking them on the plan, and then drawing them up from that to the elevation or section. Uprights are sometimes placed undcr the ridge plate to support it ; but as they take up some room, and are unsightly, and indeed unnecessary, where the iron bars (before mentioned) are made use of, they were omitted : this design is different from those commonly used. A, the elevation.

$\mathrm{B}$, the section. The flue, walk, and pit seen, with the tubs plunged in the bark; and also the columns on the pit wall supporting the rafters. 


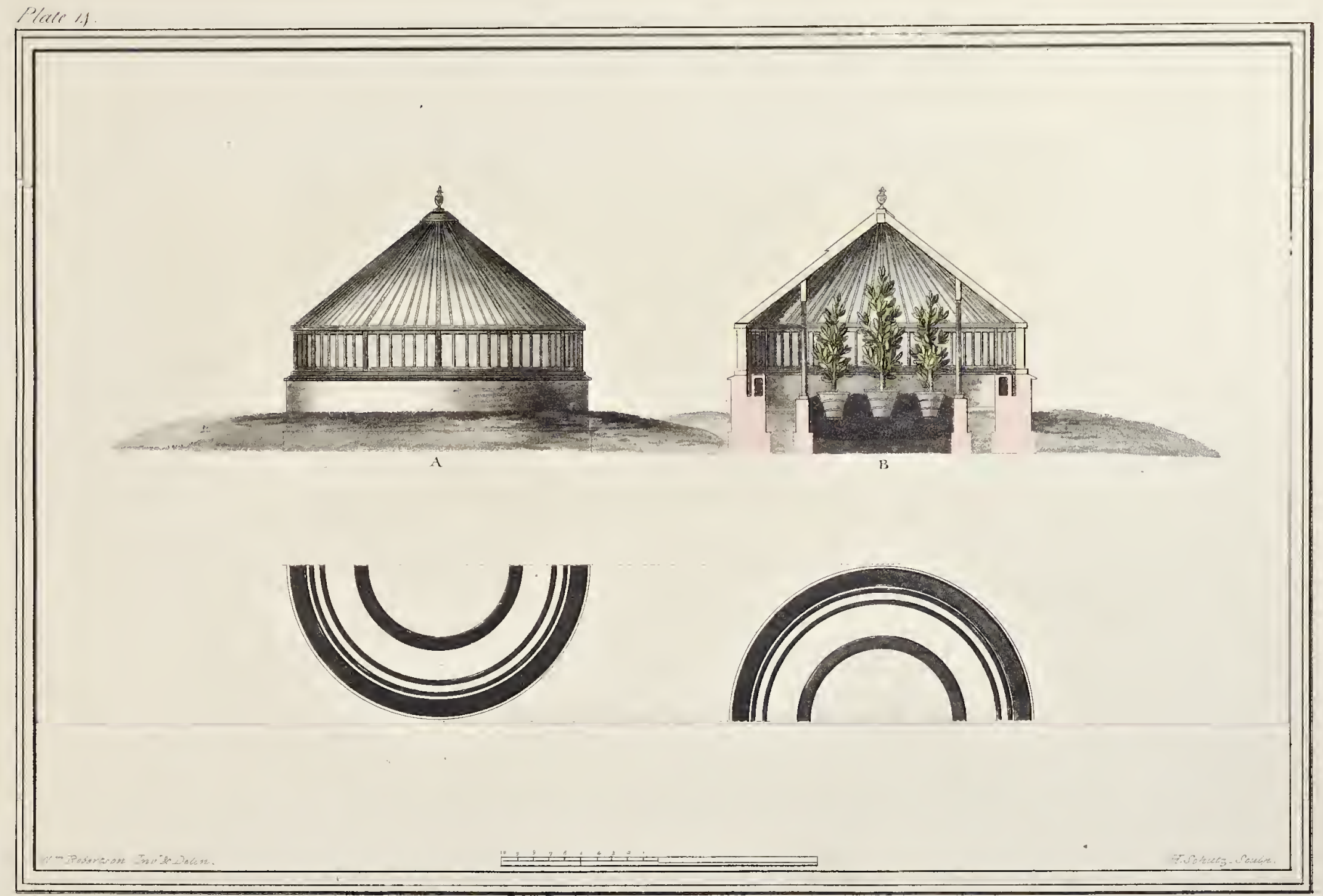




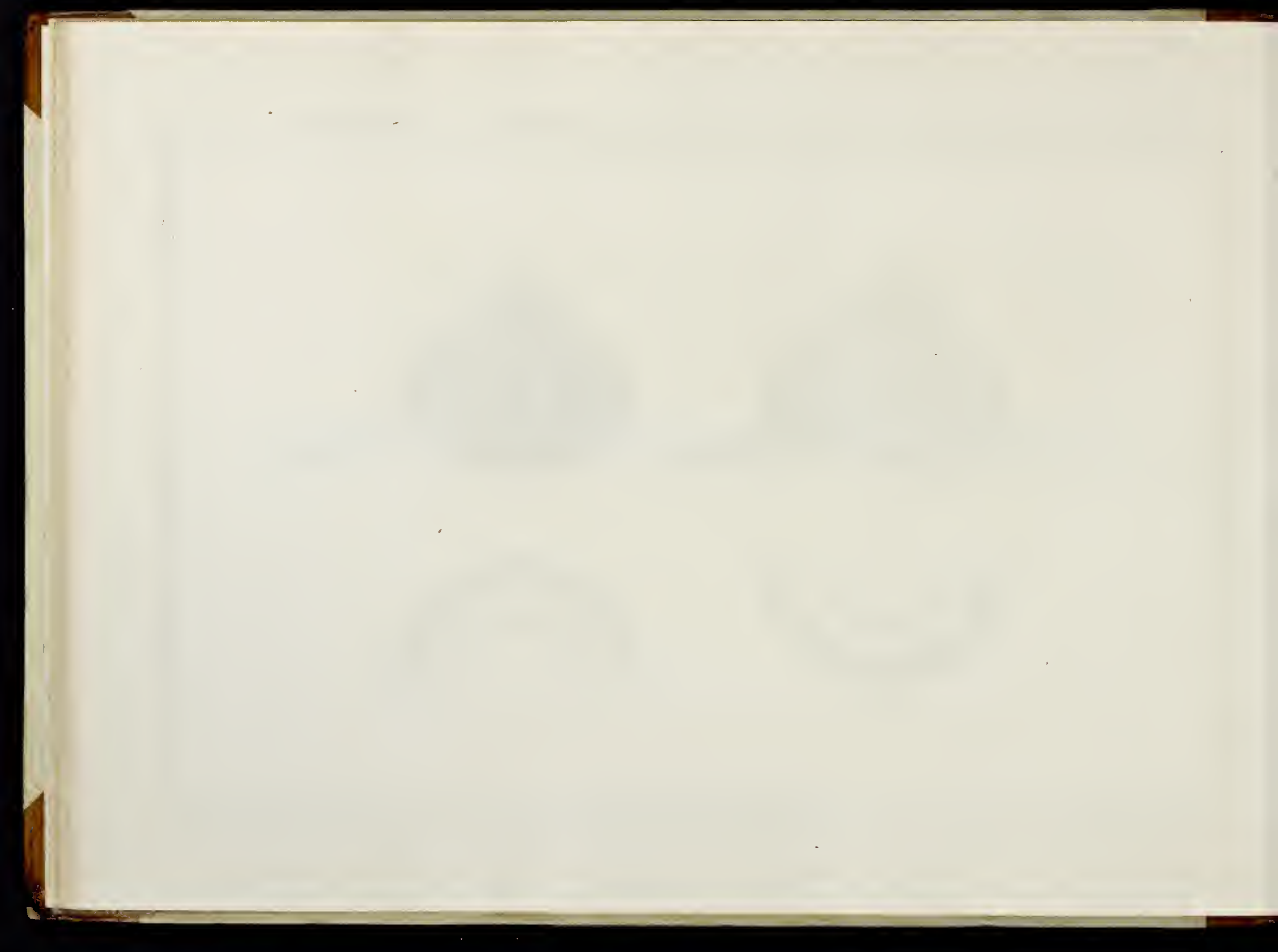




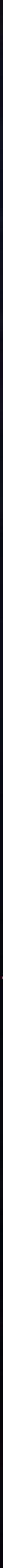




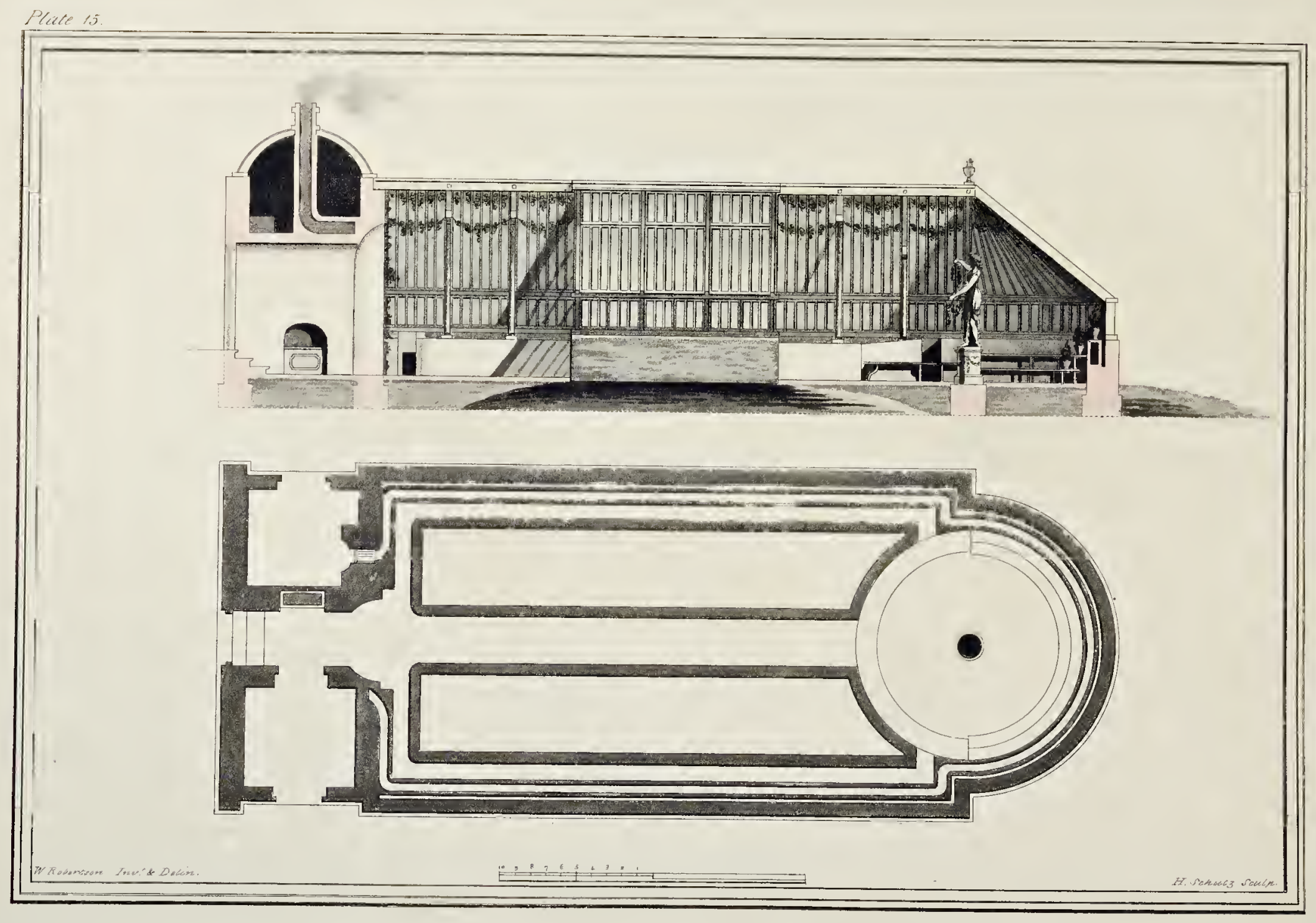




\section{PLATE XV.}

THE Plan, longitudinal section, and part of the elevation of an Ornamental Stove. As botany is a favourite study with the ladies of this kingdom, their accommodation has been aimed at in this clisposition : it is supposed to be connected with a pine stove; the ascent to it is seen on the lefthand side of the entrance, which is intended to be ornamented, and to form a centre to both the stoves. The centre walk (three feet wide) bisects the plan; and a narrow one of fourteen inches width surrounds the pits; so that they stand detached from the flues, and unconnected with each other. A small stage occupies one half of the circular end, and a bench, intended for a seat, the other. That part opposite the walk is to be moveable. A statue of Flora is placed on a pedestal in the centre. If a Passiflora quadrata be trained from the pit round the circular part, and vines (which may be planted inside) led from column to column, the weight of the fruit will naturally form them into festoons; and the statue, seen through such a vista from the entrance, will produce a very pleasing effect. 


\section{PLATE XVI.}

$I_{N}$ this Plate is shewn the manner of annexing Pine Stoves to a Green House, or Orangerie. The wall and flue of the stove, advancing on the front of the Green House, their entire width; so that the edge of the flue next the path in the stove, is flush with the end of the Green House wall ; which the short sash plainly shews, as it is exactly the width of the wall and flue beneath it. As it was thought necessary to shew all the Plates to one scale, the Green House and Stoves in this, and the Green House and Conservatories in Plate XXI. were obliged to be contracted. In the centre of the steps is placed an inclined plane, for the purpose of moving heavy orange tubs out and in with greater facility. Where the house is the length of that in Plate XVIII, it would be better not to occupy the centre, but place one at each side of it. 


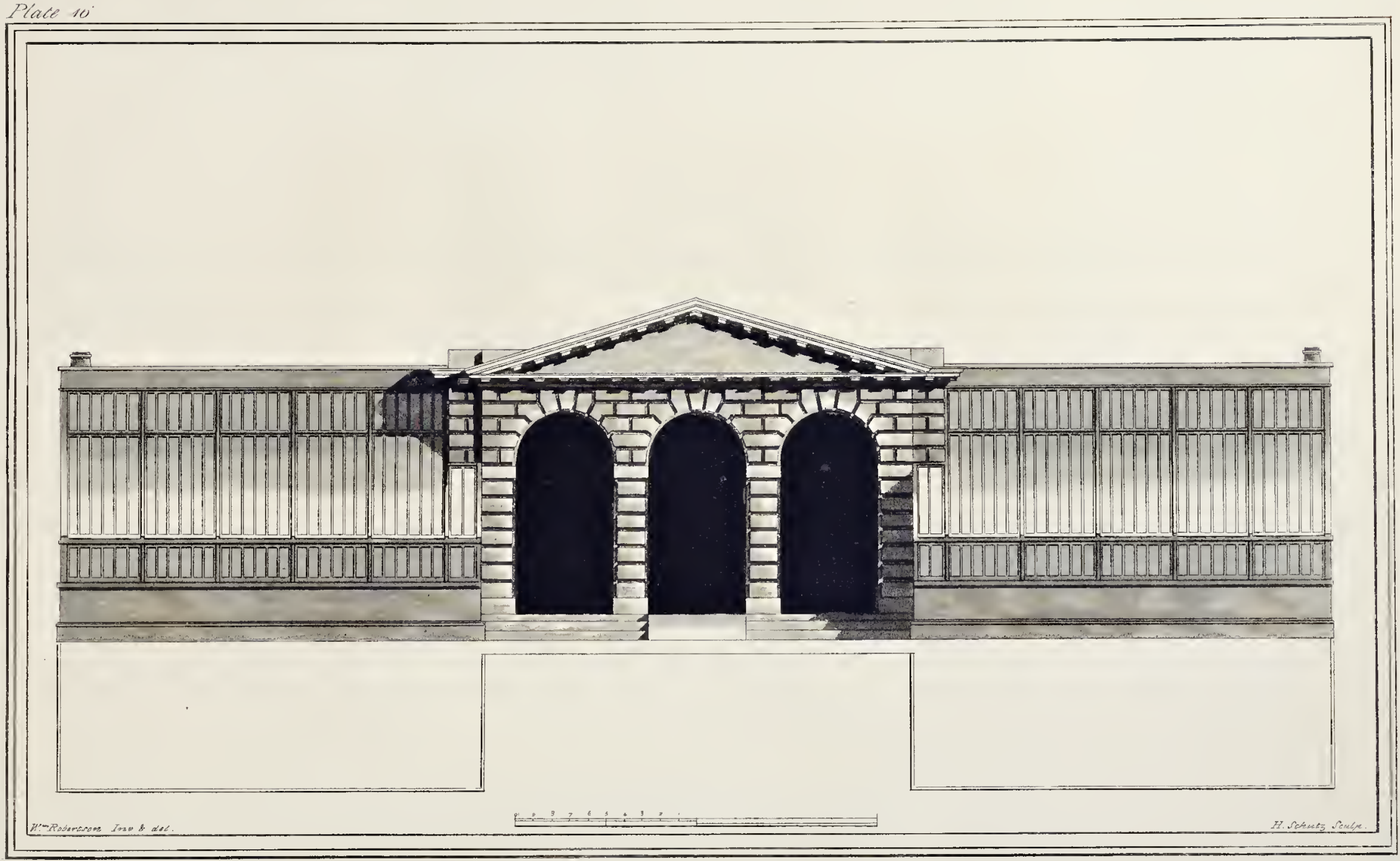




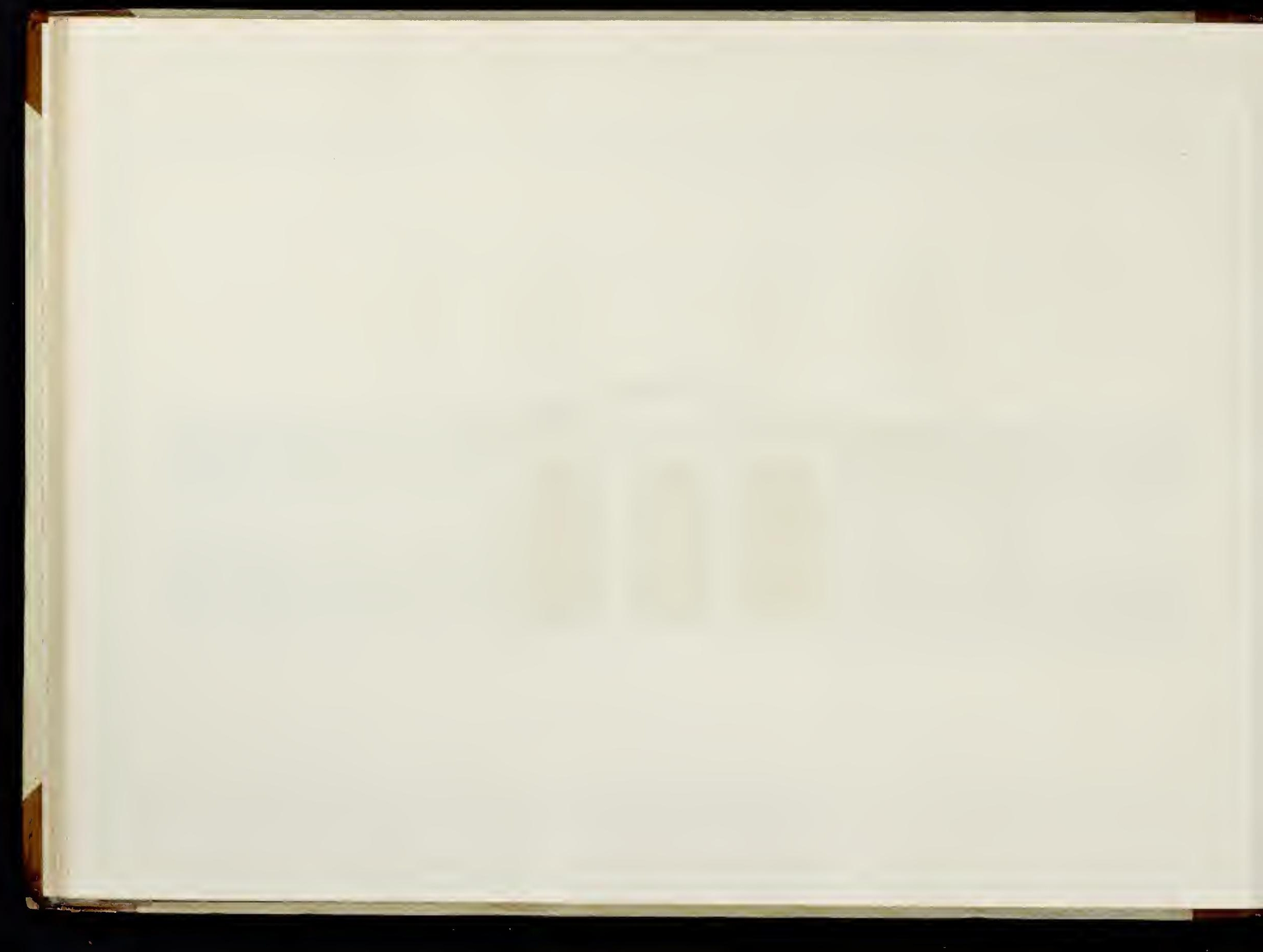




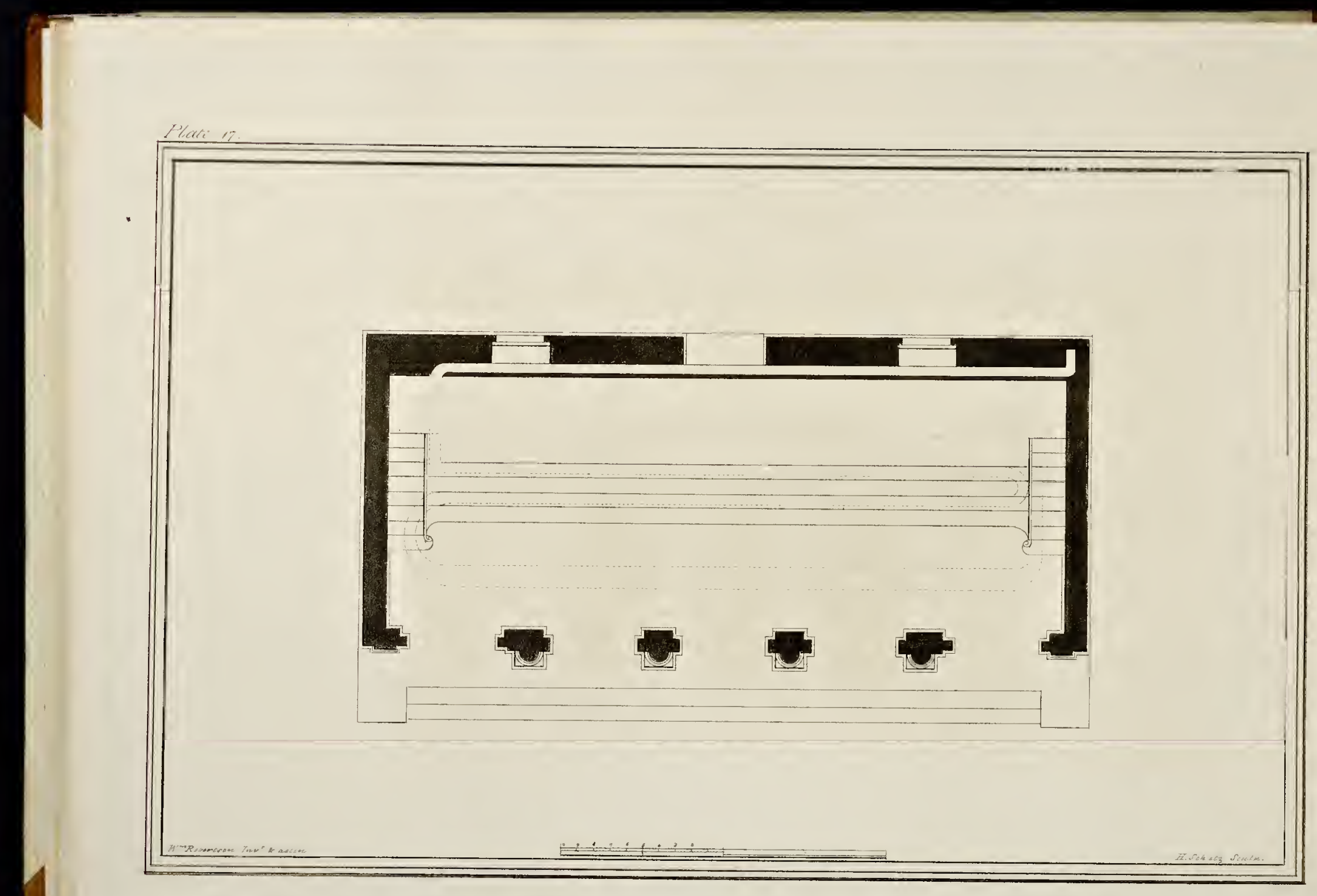




\section{PLATE XVII.}

ThE Plan of a Green House ; which differs in its internal disposition, from those in common use in this particular; that an arch of brick is introduced, in place of the wooden stage that commonly supports the plants, by which it is intended to exclude from the house, a quantity of noxious air, generated under the stage, by the constant accumulation of dead leaves, and earth brought down from the pots, by the water passing through them, after watering. Opening the sashes, in houses covered with dead roofs, will not be sufficient to dissipate it, as it is screened (in a very great degree) from the action of the external air, by the stage and plants, and is in itself denser than the external air, and consequently cannot ascend ; therefore would require a particular current, directed under the stage to remove it. Warm humid air (which is constantly circulating) is well known to accelerate the growth of plants, and swell fruit surprisingly: but cold stagnant humid air is also well known to be extremely injurious to them: without recurring to philosophical experiments, one instance can be mentioned familiar to every gardener of observation, which is, that if after watering, the house be shut for three or four days (even two), they will assume a yellow, sickly appearance, and drop their leaves, (particularly at any time between October and March, when the coldness of the weather does not require fires;) and if continued longer, their existence as plants will be endangered. The excluding such a quantity of noxious air is not the only improvement proposed by this disposition, for as the volume of air the house contains will then be considerably less, so it will require less fuel to warm it, and consequently be less expensive.

The fire place could not be shewn in the plan without confusing it, but the dotted lines proceeding from under the stairs on the right hand, express the different revolutions of the flue. For farther explanation see Plate XIX. 


\section{PLATE XVIII.}

A green house of the Doric order, and the elevation of the Plan in the last Plate, its internal disposition shewn in the right-hand section of the following one. The piers, are ornamented with rustic semi-columns, placed on a sub-plinth, and are each in width, one half the breadth of the arch, which is clouble the breadth in height. The entablature is contracted, by omitting the architrave, to lessen the dead work, and admit as much light as possible: the tread of the steps is thirteen inches, and their rise six; at the height of the three, a basement surrounds the building.

The roof is pointed and glazed on both sides, and at the ends. 


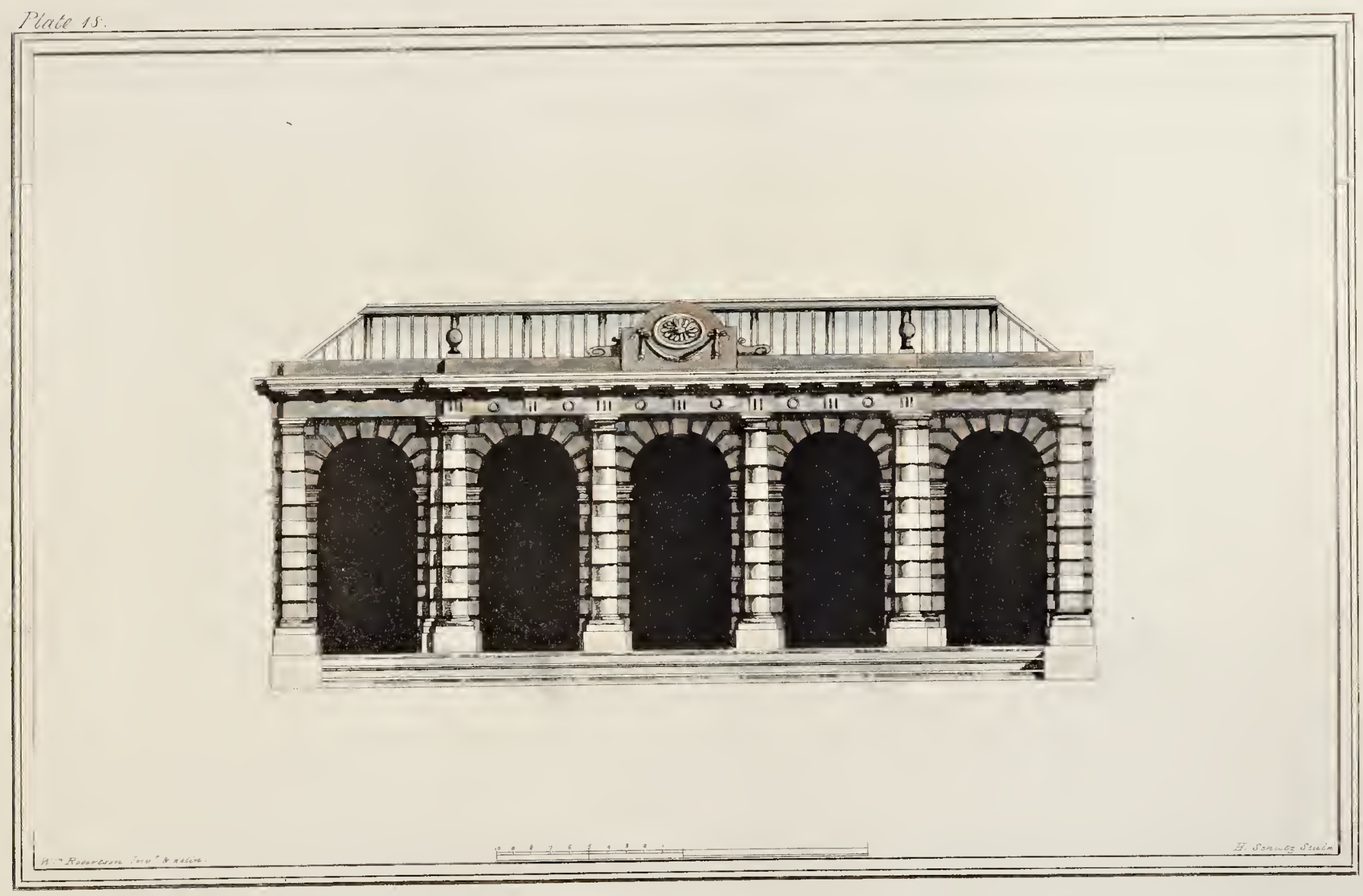




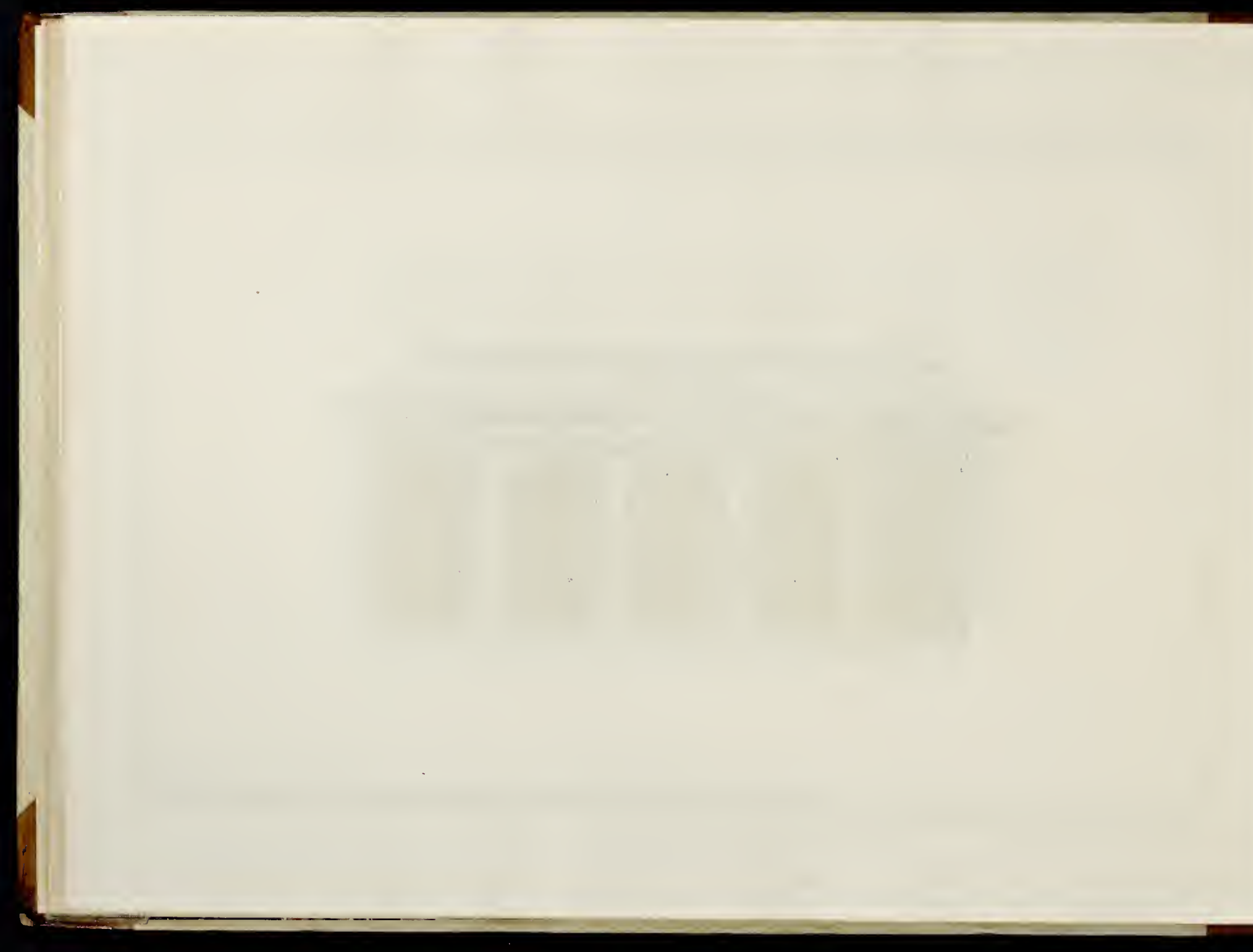




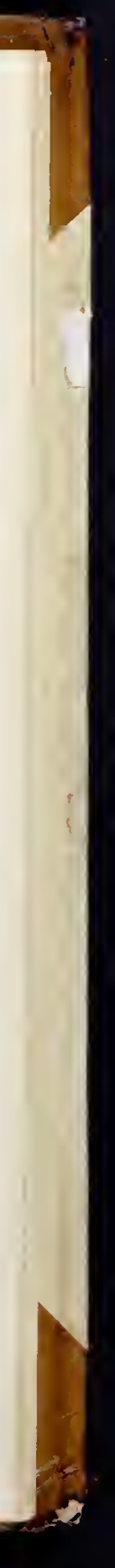




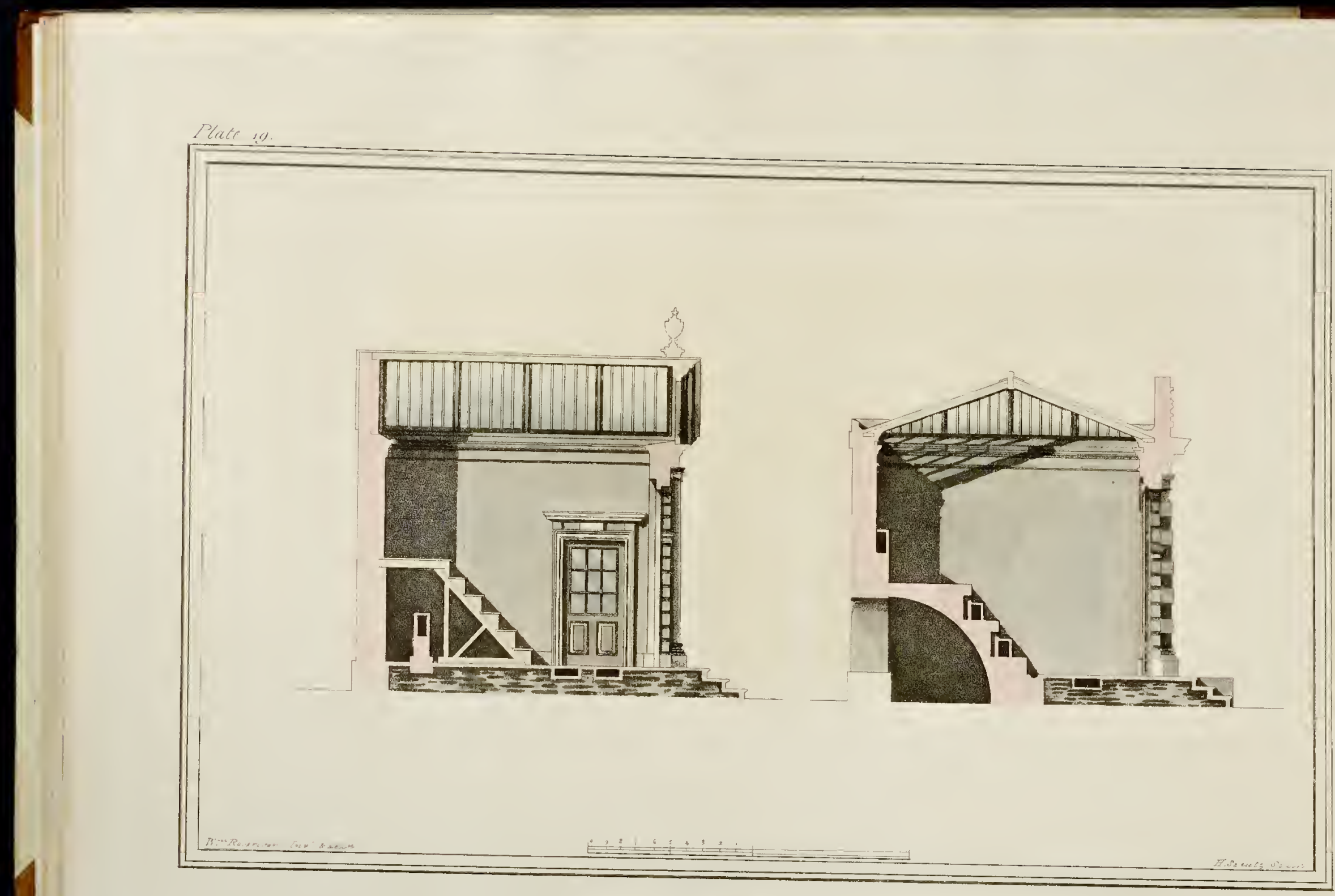




\section{PLATE XIX.}

Contans two sections; that on the right hand is the section of the plan and elevation, in the two preceding Plates; shewing distinctly the arch abutting against the back wall, and the disposition of the flues, which are disengaged on three sides, by a particular contrivance, that as little of the heat may be lost in the dead work as possible; this is shewn clearly in Plate XXIII. at fig. C, where the apertures over the flue, through which the heated air from the cavity behind it enters the house, and the intervening bricks, to support the overhanging dead work, are seen. The form of the arch is the quadrant of an ellipsis; its thickness at the crown, the length of a single brick, the covering tiles and their bed not included; the head of each of the flues is inclined a little outwards, that the water which shall pass through the pots, may quickly run down into the groove, seen at the bottom of the first step, and be by it carried out of the house. The vault is intended for a coal shed, and for making the fires in. 


\section{PLATE XX.}

Elevation of another Green House, differently ornamented from the last; the piers are rusticated, and only one third the breadth of the arch in width; the height of which is clouble its breadth, and is decorated with a regular impost and archivolt. The roof is pointed, and the soffit of that part represented leaded, is intended to be ornamented, for the purpose of hiding the iron braces, before described.

The plan of the front, is underneath it. 


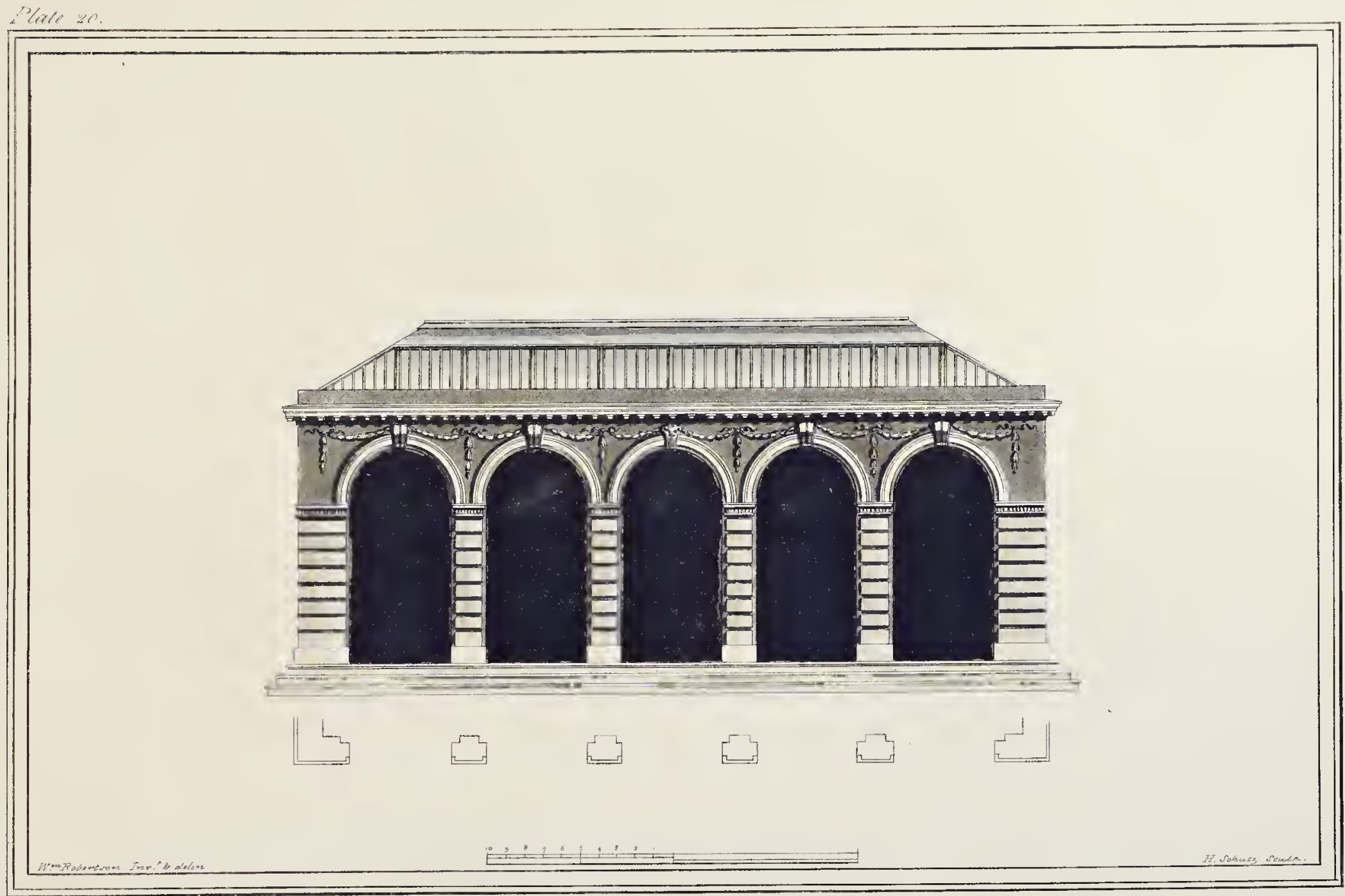




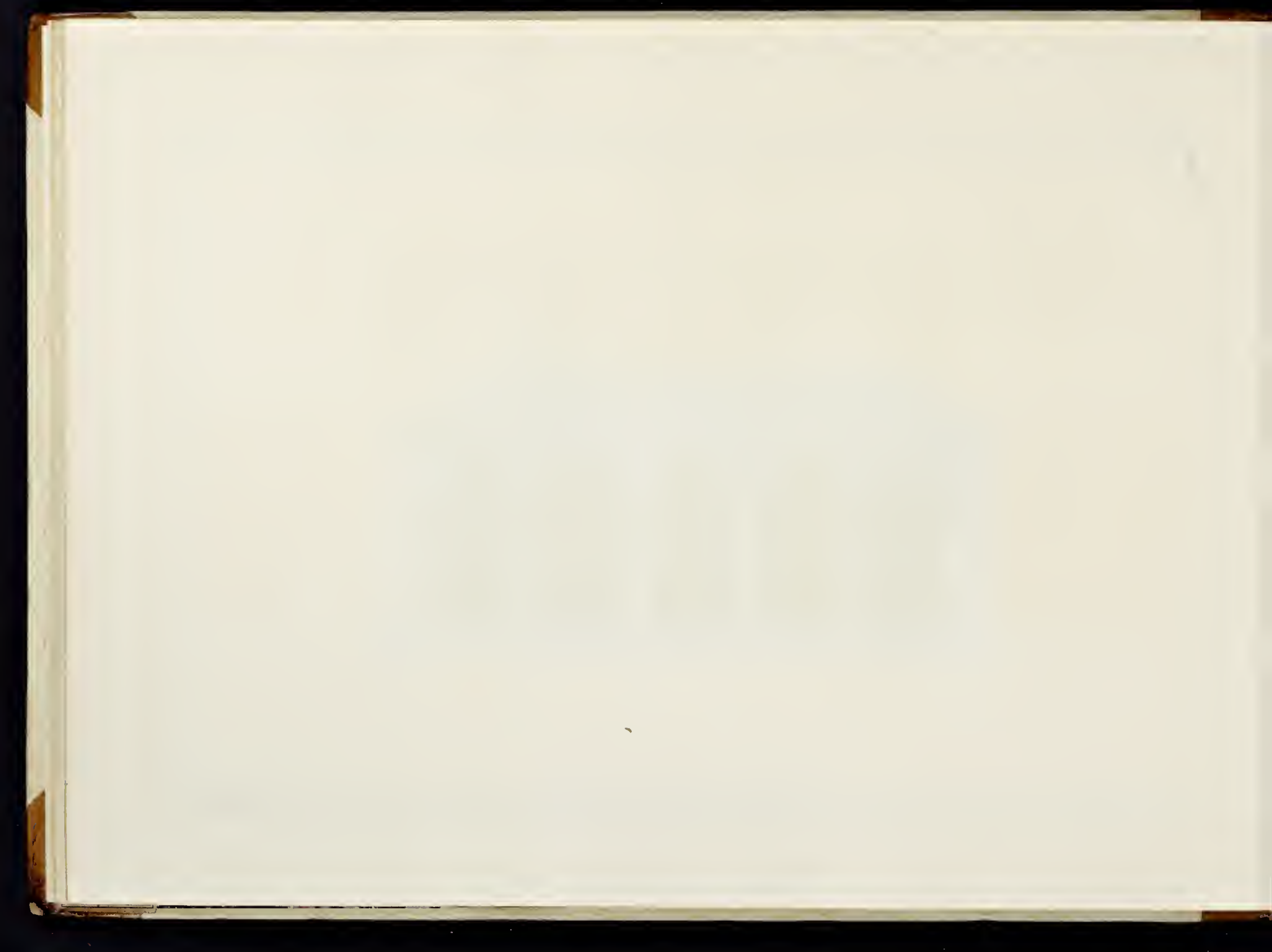




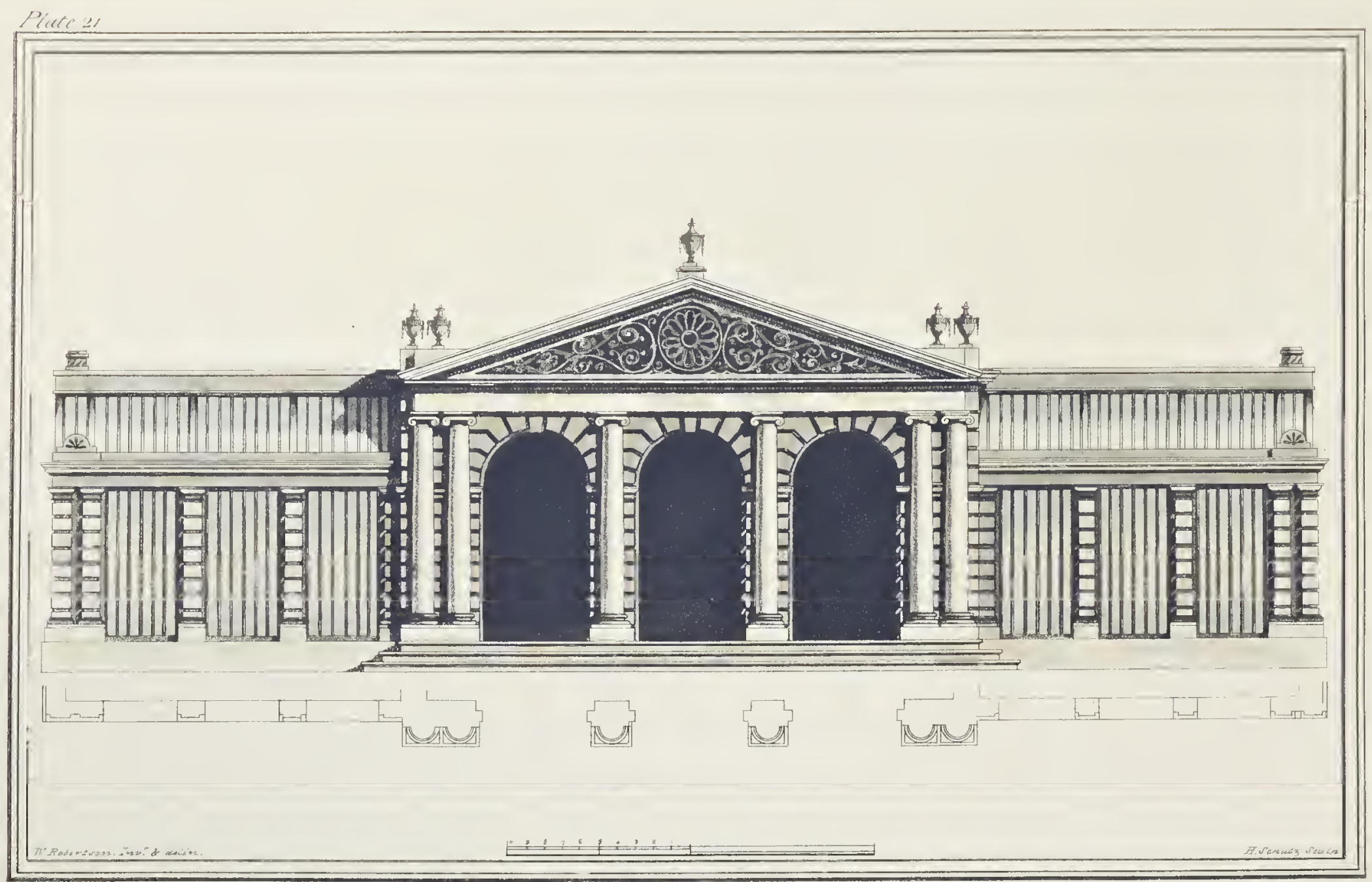




\section{PLATE XXI.}

A small Green House, and two Conservatories. The Green House decorated with antique Ionic semi-columns, carrying a pediment, the tympan of which is glazed. The Conservatories, with rustic pilasters, symmetrizing with the piers. The slope of the roof follows the inclination of the pediment, and is glazed, as seen in the left-hand section of Plate XIX. where a stage, such as those commonly used, is seen, with a flue beneath it; the effect of which may be said, perhaps, to do away one of the objections made to this disposition, in the description of Plate XVII; and it is admitted, if the fire be kept up (which is well known not to be the case) during the winter, but even so, the other will still remain in force, for there will be an unnecessary expenditure of fuel, to warm a body of air, the absence of which can be well dispensed with.

The entrance to the amnexed Conservatory is seen in the section; and the plan of the front, underneath it. 


\section{PLATE XXII.}

Contains the principal parts that a Stove is composed of, at large. A scheme, contrasting a right lined wall to an angular one; and shews a method of framing the timbers of stoves, different from the common. At A, is seen the dove-tail piece, mentioned in the description of Plate III. and part of the studs brought up in the wall, on which the plate is morticed, to prevent its being pushed out by the pressure of the sashes. At B, is shewn the section of a back wall, where the head of a rafter is seen tenanted into the wall-plate, and intended to be pinned down through it: behind the plate, at fig. 2 , is seen a stud brought up in the wall, to which the plate is morticed and run down on it ; the end of the stud should be at such a distance from the flue as to prevent any possibility of its taking fire. The head of the stud is shewn at fig. 2, off the section : the wall-plate and studs are again shewn off the wall, at the bottom of the plate (fig. G.) ; these last may be at the distance marked 7 and 8, from each other: this method will be found useful, when the wall is only coped, and has no parapet, the weight of which tends to keep the rafters in their places, and take off the oblique pressure of the roof on the front, which can be effected in this manner without it. Fig. I is the section of the rafter at the lapping of the sashes; fig. 3, of the lower part of it. At $\mathrm{C}$, is shewn the front framing of the Peach Stoves in Plate I and V. and the manner of fixing a moveable treillage; the pivot at its bottom is placed in the hook seen in the bottom of the rafter; and the head of the treillage moves on the iron segnient seen fixed to it. Upon the upper side of the rail of the treillage (in the circle), is shewn its pivot, and the nut and screw to adjust its distance from the glass, for colouring the fruit, or any other purpose. The treillage ought not to be of one piece, but divided into lengths of the breadth of three lights each, which is as much as a tree generally extends. At fig. 6 , is shewn the manner of running the front sashes. At $\mathrm{E}$, is shewn the lower 


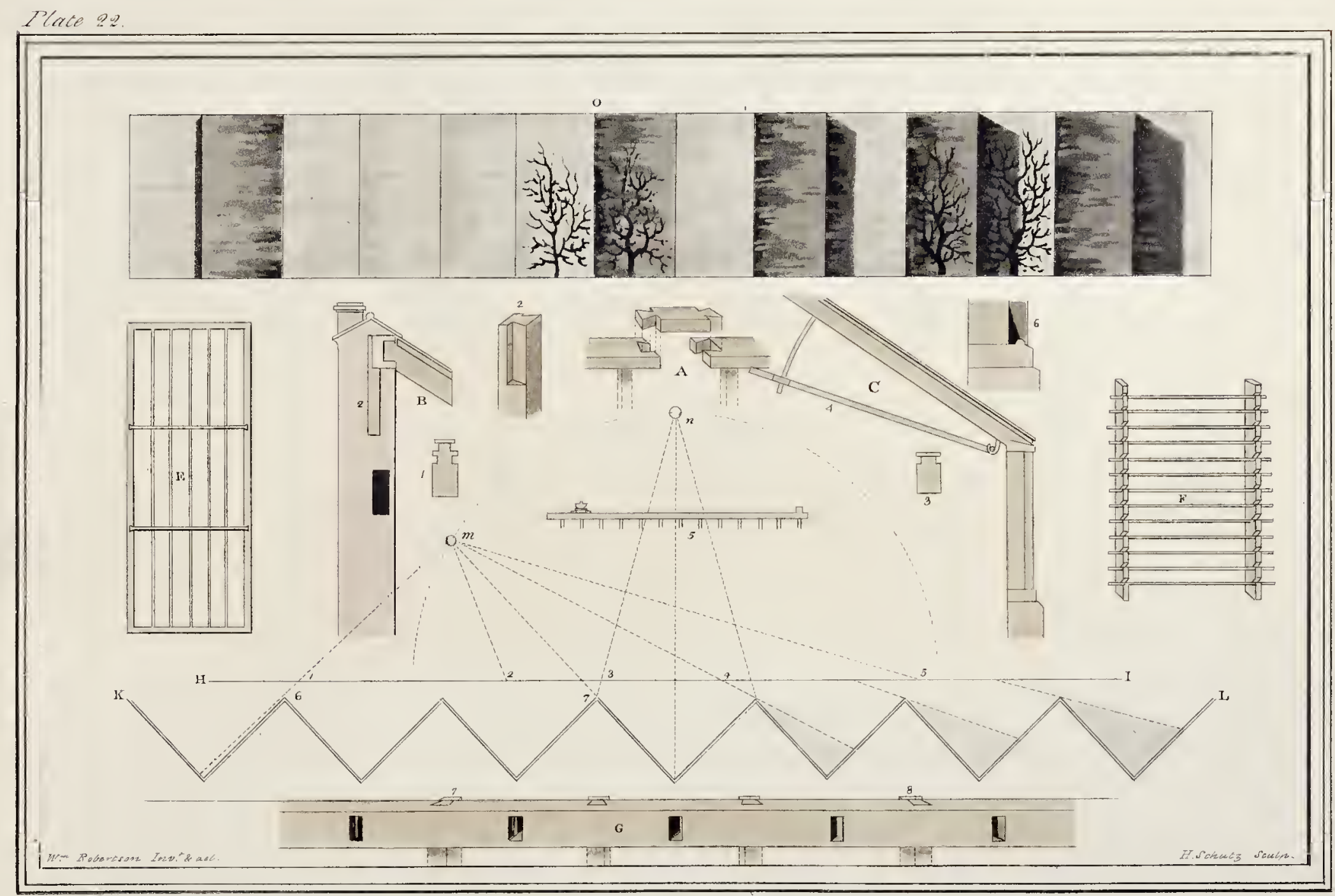




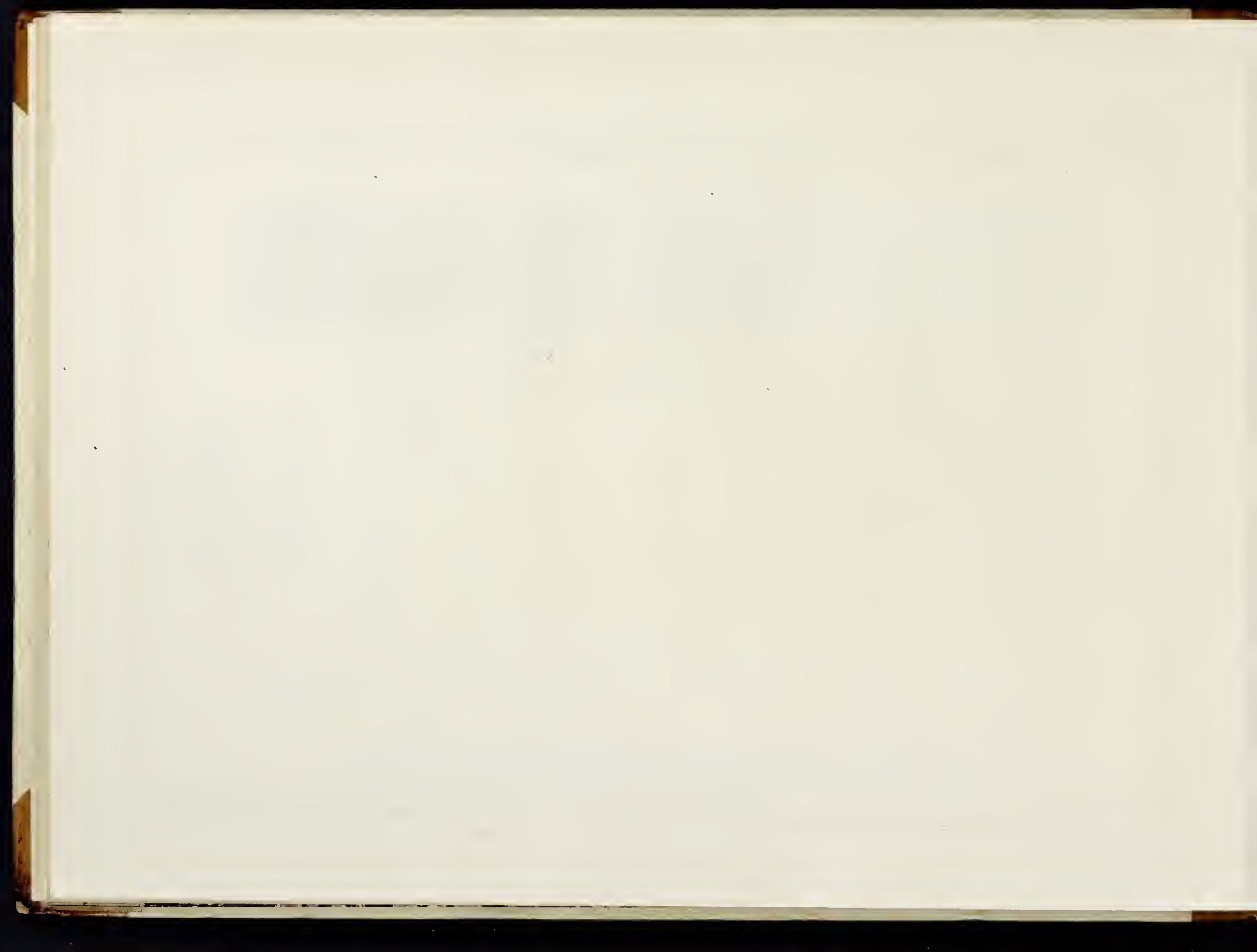


PLATE XXII.

sash of a roof, strengthened by two iron bars, to prevent its sagging, on account of its length, the short head sash should have one. At F, is part of such a treillage as is placed against a back wall. $\mathrm{H} I$ represents a right lined wall. K L beneath it an angular one. All the rays proceeding from the sun, at $m$, are seen to illume every part of the first, while no more than one half of the last is enlightened by them: that part only between the figures 6 and 7 , directly opposite the luminary, is without shade; and the shadows projected by the several angles towards $L$ are seen increasing as they are more remote from it. In this scheme the sum of the shades will be found equal to the sum of the enlightened parts; but if the plate would adınit of its being continued, they would by far exceed them ; and in that case the proportion would be the same, though the sun, at 21 , was placed as high as the plate would admit, in the line $n$ produced : therefore this disposition is very disadvantageous in spring, when the sun is not far above the horizon, and his light as well as heat particularly wished for. At $O$ (the top of the Plate), is the elevation of the angular wall drawn up from the plan, where what has been advanced is again made evident. 


\section{PLATE XXIII.}

Contains several hints for improvements. At A, a manner of hanging the head lights is shewn, by which the ventilating of the Stove is greatly facilitated; a line is fixed to the centre of the sash, (fig. 1.) and carried over two small pullies in the head of the wall, into a groove at the back, (closed with single bricks, to be removed occasionally) where a weight is suspended from it, which should be heavier, than what is sufficient to overcome the weight and friction of the sash; that when raised, it may not be shaken down by high winds: to the under part of the side rail of it, is fixed a rack, (fig. 2.) and to the rafter under it, a spring latch: to give air, the sash is pulled down (by catching its bar with a hook fastened purposely on the head of a rod) and the latch, catching the teeth of the rack, prevents it from ascending : to shut the stove up, the latch is pulled down, by its button, and the sash ascends of itself on its rollers.

As the external application of shutters, \& $\mathrm{c}$. to the glass roofs of Green Houses, is attended with much inconvenience, and when done not perfectly safe; at B, and the longitudinal section underneath it, is shewn a manner of effectually protecting the plants, attended with little trouble, when once fixed." At 9,9 , in the section are seen cavities the entire length of the end walls, capable of containing (without touching its sides), ten, fifteen, or twenty yards of painted canvas (as the length of the house may require) rolled round a long roller of wood, which turns on its ends, from which weights are suspended by cords, (as shewn) the outside edge of the canvas is attached to a slip of wood, as long as the house is wide, with a small roller at each end (as seen in the groove, above the cornice in B), its thickness an inch, and width two and a half, the nose of the

* No vines are supposed planted in this house, but it can be applied even where there are. 

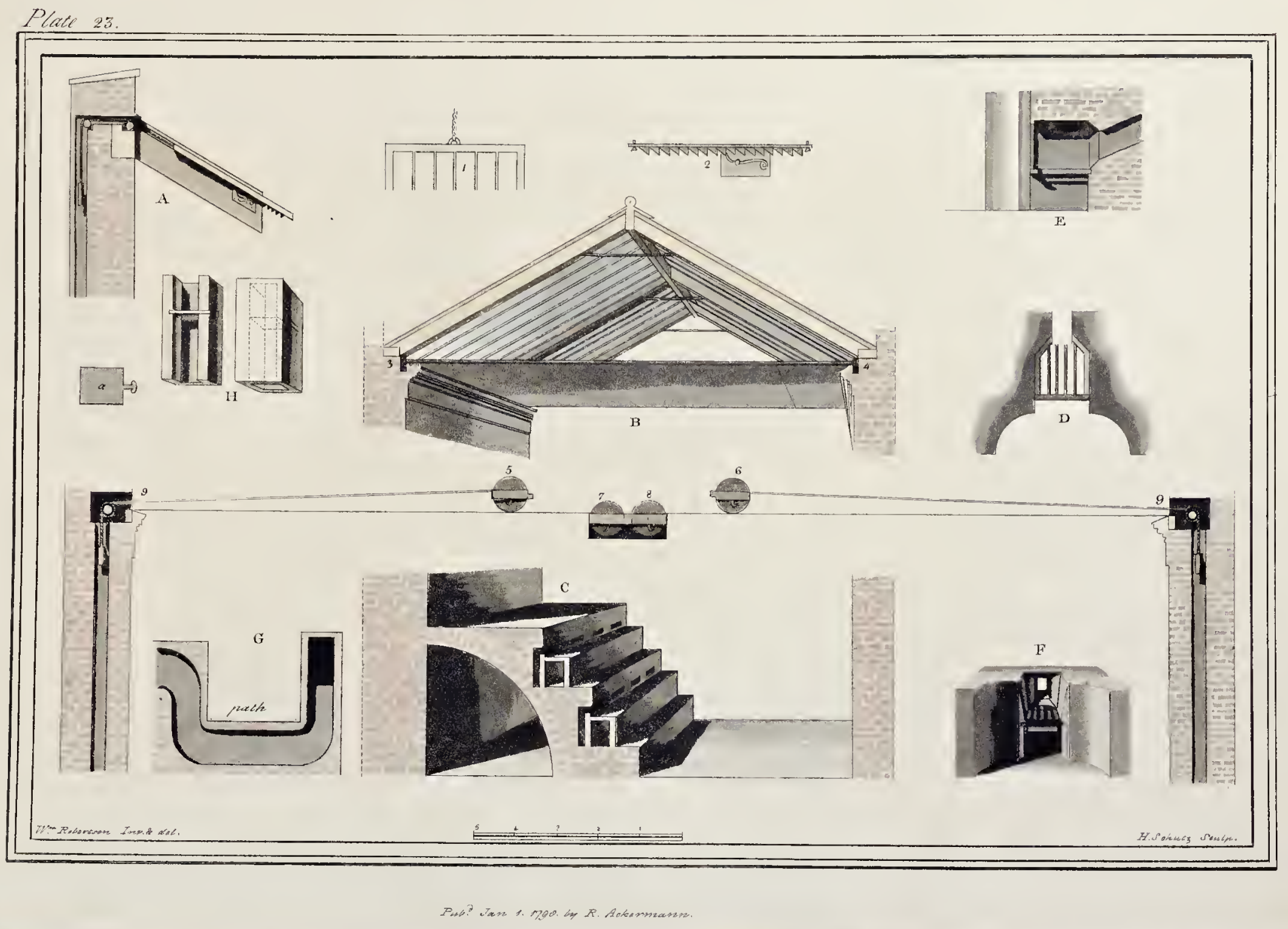


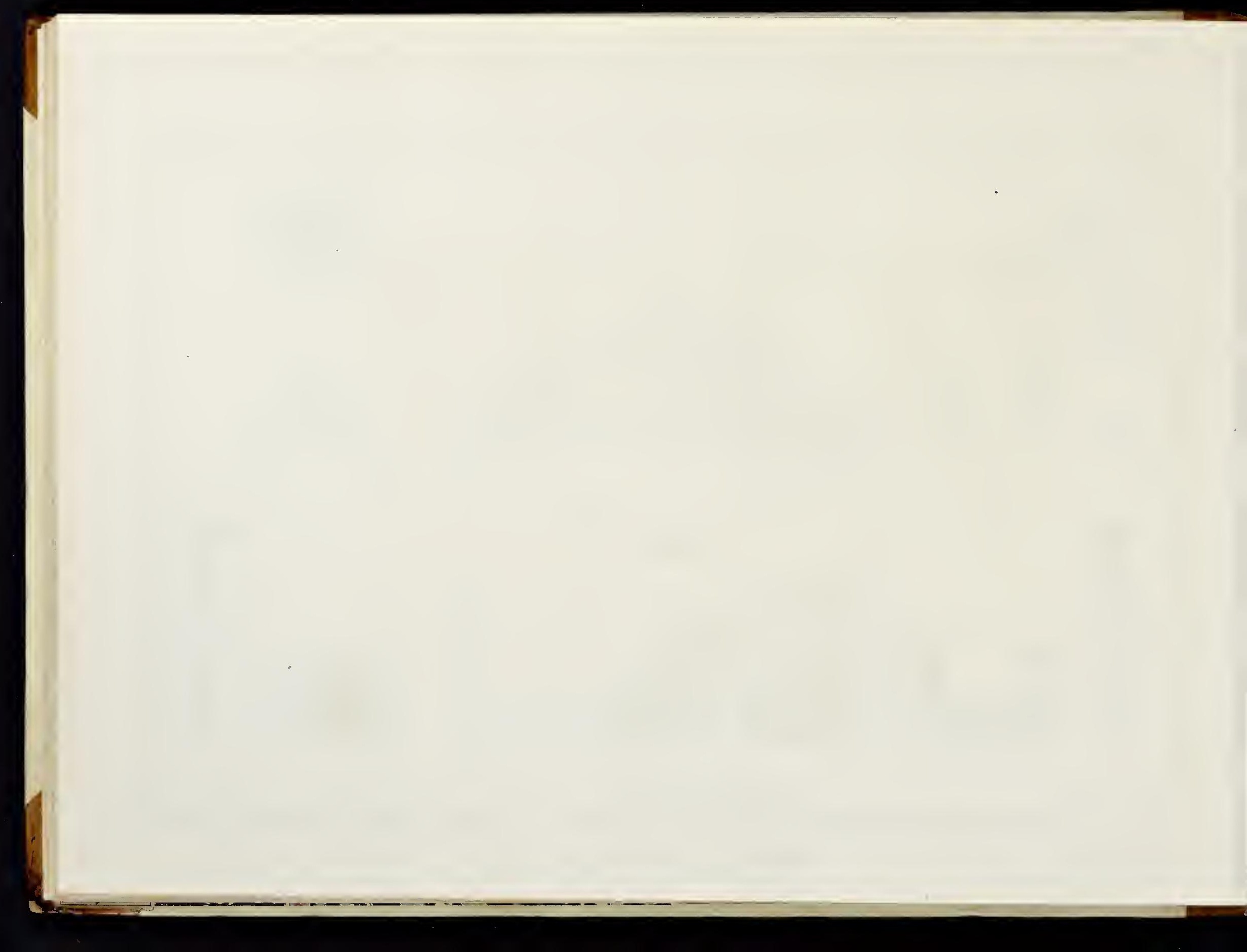




\section{PLATE XXIII.}

slip projects beyond its roller, as seen at 5,6 , that when fallen into the cavity they may lap over each other, as at 7,8 ; - the cavity is placed midway the house, and a little deeper than the semidiameter of the roller, that it may not be pulled out of its place by the weights; as they will then act nearly at right angles on it, (the roller and slip are together called the rumer) the ledge, which keeps the rollers in their places is removed, that the whole may be seen distinctly : to close the house, the runners are pulled forward (by the contrivance beforementioned) until they fall into the cavity, where they remain. To uncover it, the lower runner is pushed up, and both return to their places at 9,9 , by the descending of the weights. That the canvas and roller may be entirely taken out of the cavity,(it should run through the front, but be stopped only when wanted), lest they slould rot; the canvas has holes worked in it, and the edge of the runner buttons on it, so that they may be readily disengaged from one another; at the bottom of the grooves, where the weiglits descend, should be small holes stopped with a loose brick (plastered over), to take out the weights if the cords should break. At D, is shewn the plan of a furnace; $\mathrm{E}$, its length section; and $\mathrm{F}$, its elevation in perspective. Having the bottom of the flue on a level with the bottom of the furnace, may be justly esteemed an error, even when coals are used, but a very great one where wood or peat is the fuel burned; for the ashes being then carried in by the draught, will with the soot, soon choke the flues; to avoid this, the flue should ascend directly from the furnace, (at the very least) in an angle of thirty degrees, and may be so much as sixty; the flue should be narrower at its throat than elsewhere, and then, though the bottom of each revolution was on a level, or such dips as seen at $G$, continued round the stove, the heated air would be forced through them; at the end of the furnace the sides are all inclined to the flue, that none of the rays may be reflected, but directed to it as a 


\section{PLATE XXIII.}

centre. The furnace should never project beyond the back wall in any of the degrees, shewn in the sections of Plates I, II, III, \&c. unless there is a sufficiency of dead work above them, (as in section of Plate V.) to prevent the heat escaping.

At $G$, is shewn the dipping flue of Plate $V$. at large, which many think impracticable; but a little acquaintance with pneumatics will convince them of the contrary.

At II, the damper referred to in Plate VIII. is shewn in a part of the funnel or chimney; it should be placed on the outside, as high as a man can reach with ease, and should slide in an iron frame; according as this is opened or closed, after the cold heavy smoke is passed, more or less heat will be thrown into the house. 



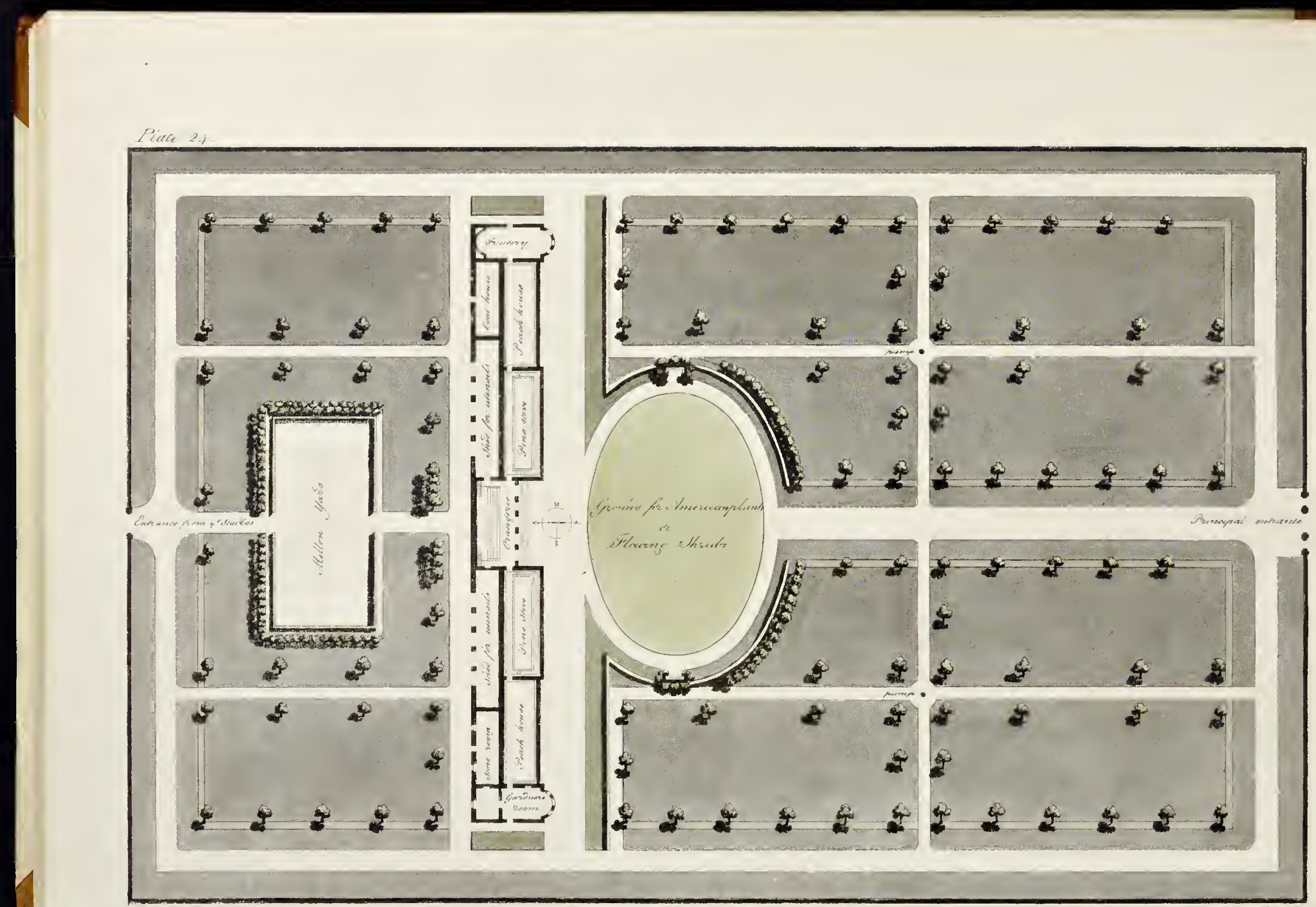




\section{PLATE XXIV.}

A PlAN of a plain Kitchen Garden (its form accommodated to that of the preceding Plates), not intersected by cross walls; as those that surround it, (together with the espaliers) are expected to produce as much fruit (from trained trees), as is necessary. The range of stoves consists of a Green House, two Pine Stoves, and two Peach Houses: two small pavilions terminate the ends; in one of which are the gardener's apartments, the other is designed for a fruit room, for the reception of the family when they visit the garden, and intended to be ornamented. Opposite the centre of the range is a large oval for American plants and flowering shrubs; the plan of the statue of Vertumnus is seen in its centre, and at each end of it, a garden seat is placed. The Melon Yard for framing, is placed behind the stoves, next the entrance from the stables; that all the litter which attends it may be kept out of sight. Pumps are placed in the centre of the principal quarters; and if there is much framing, there should be another in the Melon Yard. From the entrance, the Green House only is seen, with the statue opposed to its centre void, which would have a very pleasing effect, as the remainder is concealed by the screen from the view. It was thought unnecessary to shew the minute subdivisions of the quarters.

The names of the several parts are marked on the plan; and the measures may be found by the scale at foot.

N. B. The Second Part of this Work will contain Original Designs, for Entrances to Parks, Temples, Baths, and other buildings, used either for ornament or utility in Gardening. Each Number will terminate with a View, descriptive of their situations, agreeable to their different characters. 


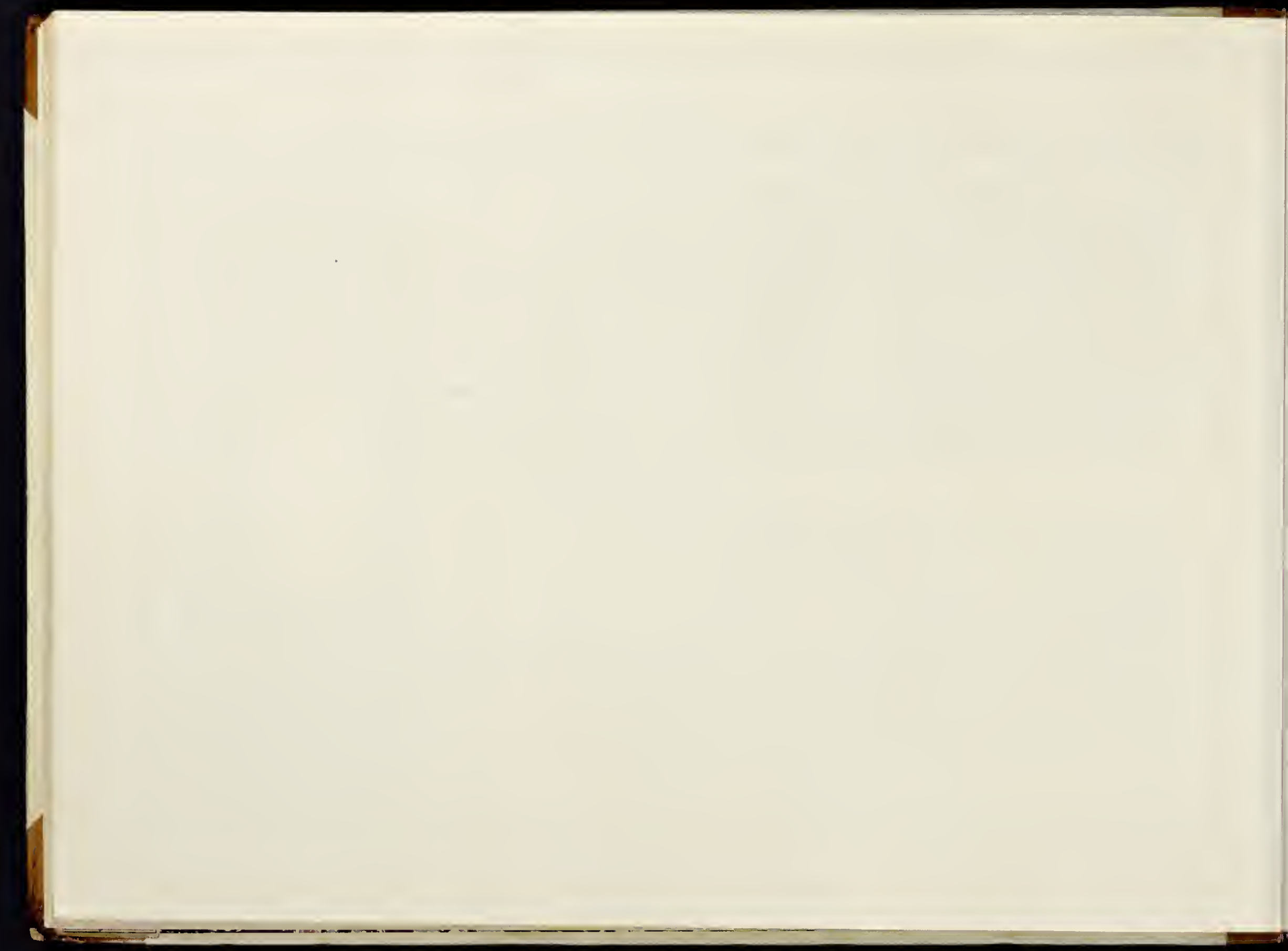





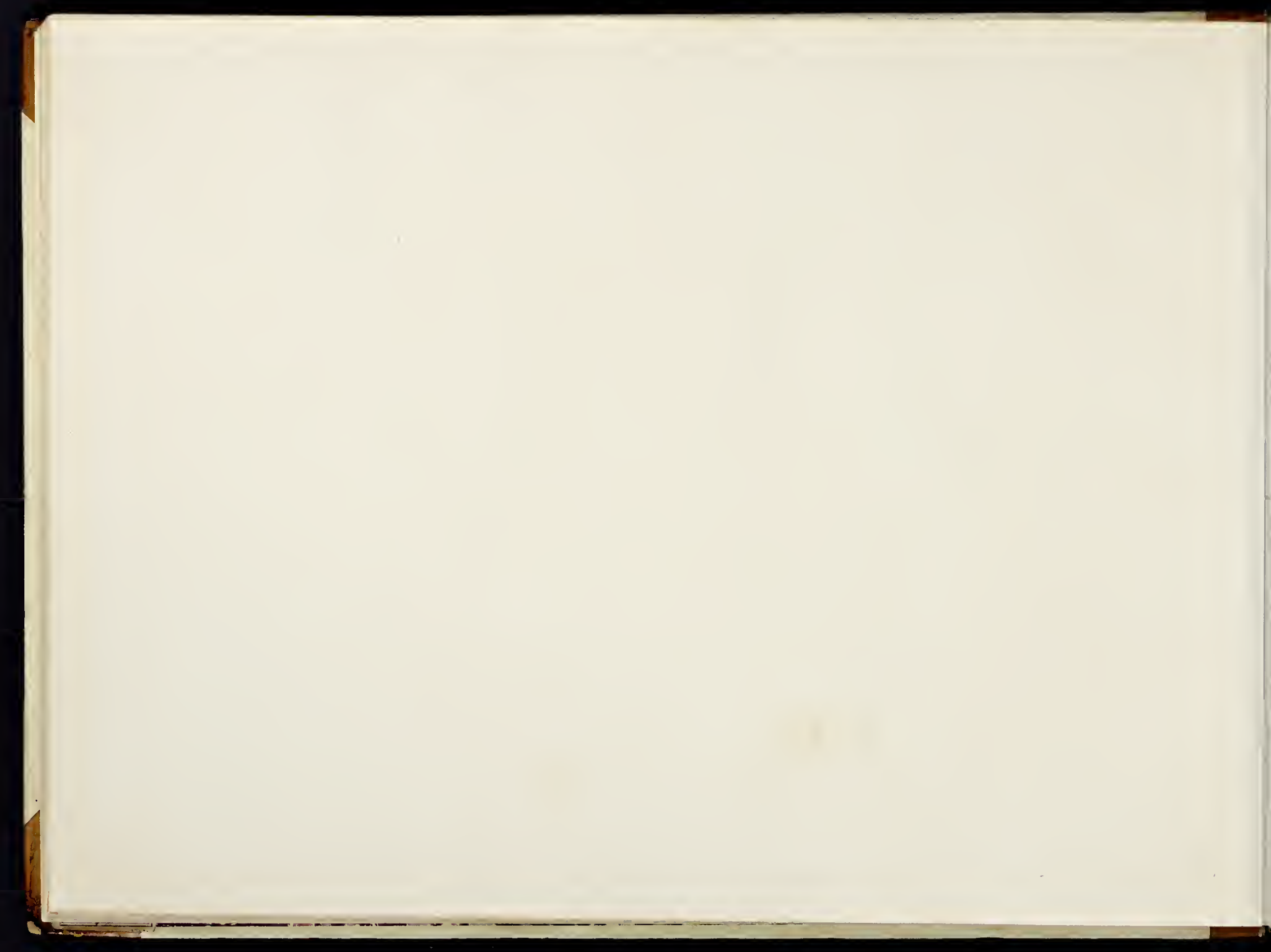





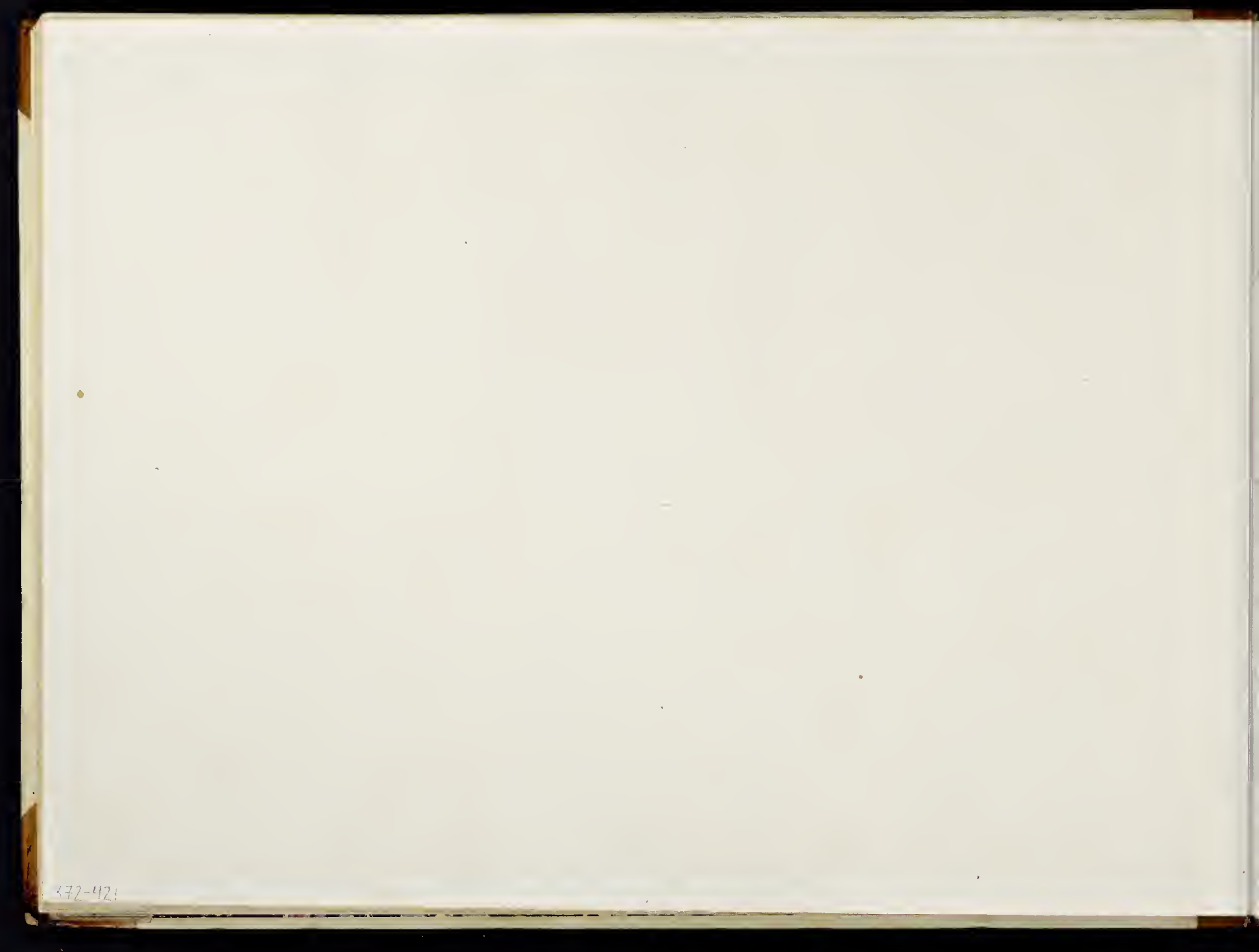




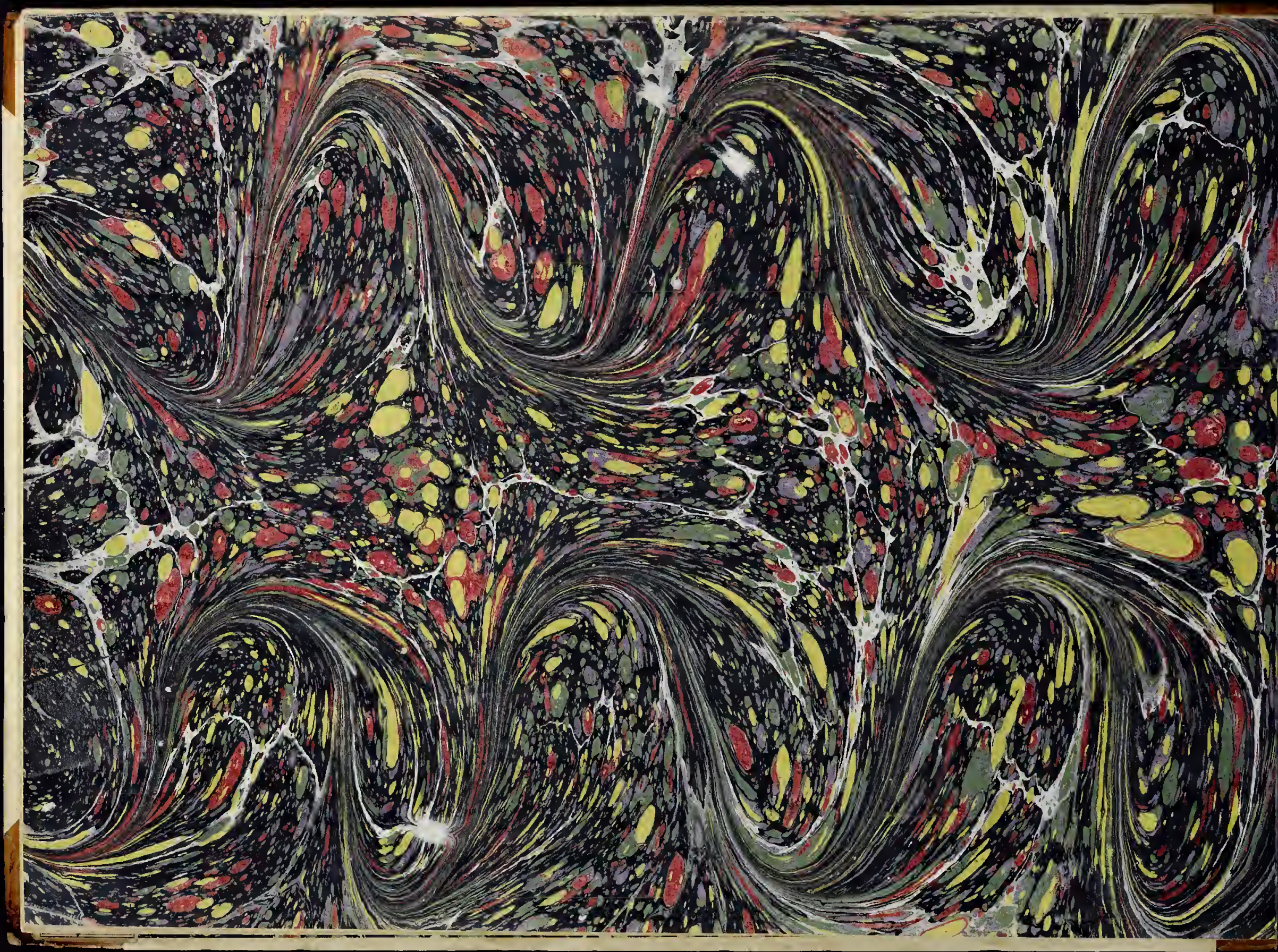




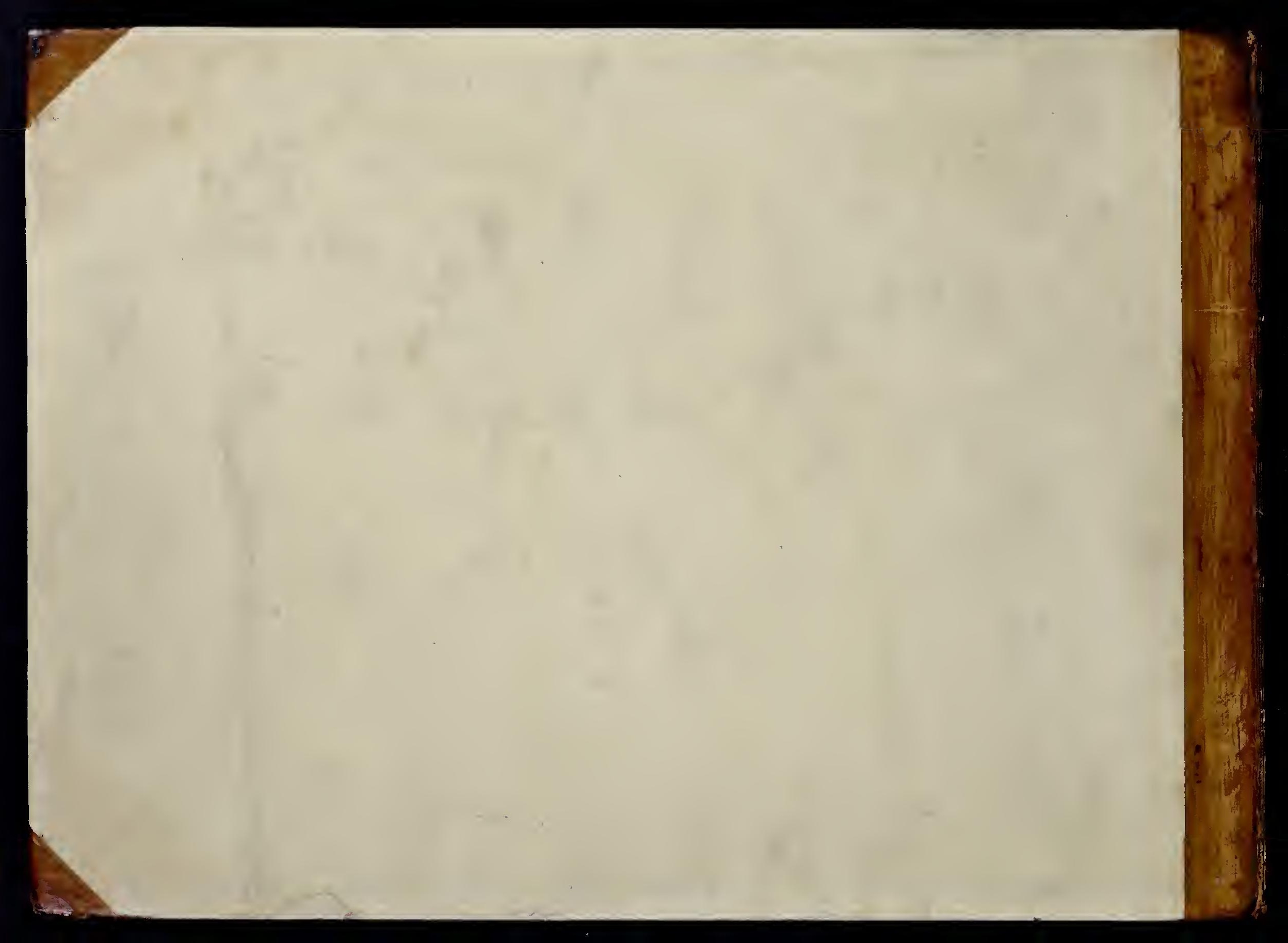

